\title{
What it means to be phonetic or phonological : the case of Romanian devoiced nasals*
}

\author{
Benjamin V. Tucker \\ University of Arizona and University of Alberta
}

Natasha Warner

University of Arizona and Max Planck Institute for Psycholinguistics, Nijmegen

\begin{abstract}
phonological patterns and detailed phonetic patterns can combine to produce unusual acoustic results, but criteria for what aspects of a pattern are phonetic and what aspects are phonological are often disputed. Early literature on Romanian makes mention of nasal devoicing in word-final clusters (e.g. in /basm/ 'fairy-tale'). Using acoustic, aerodynamic and ultrasound data, the current work investigates how syllable structure, prosodic boundaries, phonetic paradigm uniformity and assimilation influence Romanian nasal devoicing. It provides instrumental phonetic documentation of devoiced nasals, a phenomenon that has not been widely studied experimentally, in a phonetically underdocumented language. We argue that sound patterns should not be separated into phonetics and phonology as two distinct systems, but neither should they all be grouped together as a single, undifferentiated system. Instead, we argue for viewing the distinction between phonetics and phonology as a largely continuous multidimensional space, within which sound patterns, including Romanian nasal devoicing, fall.
\end{abstract}

\section{Introduction}

Several decades of research in Laboratory Phonology have demonstrated that a wide array of factors in the speech system, e.g. syllable structure and assimilation, contribute to the exact surface form which a speaker produces for a particular token of a particular word. This paper examines how we categorise these factors as phonological or phonetic, using devoicing of Romanian cluster nasals as the test case. Some of the factors that affect pronunciation seem to be rather abstract, perhaps categorical, and are

* We would like to thank Diana Archangeli, Jordan Brewer, Ioana Chitoran, Mike Hammond, Diane Ohala, Adam Ussishkin and three anonymous reviewers for helpful and insightful commentary of this work. Special thanks to James S. McDonnell Foundation grant \#220020045 BBMB and to Diana Archangeli and Jeff Mielke for their help and support in use of the ultrasound. 
termed part of the phonology. Others seem rather 'low-level', perhaps gradient or more variable, and may be considered phonetic. However, a great many phenomena are difficult to classify in this way, and researchers usually do not agree about which criteria suffice to place a phenomenon on one side or the other of the phonetics-phonology line. In fact, some researchers maintain that there is no line, because all sound patterns are part of the same system or processing mechanism (Steriade 2000), or because the two areas are more a single field than separate ones (Ohala 1990). The current paper uses several phonetic measures to determine what factors contribute to devoicing of nasals in Romanian. It then uses this case, because it is an unusual alternation that has not been well documented before, to examine the interaction of phonetic, phonological or mixed influences. We suggest that rather than there being distinct phonological and phonetic domains, or even a single domain of all sound variability, there is a continuum or a collection of several dimensions from the phonetic to the phonological. We examine the prosodic boundary hierarchy, syllable structure, assimilation to a neighbouring segment and paradigm uniformity as variously phonetic and phonological factors that may contribute to Romanian nasal devoicing.

Romanian nasal devoicing is an allophonic alternation that was pointed out in early instrumental phonetic work. Petrovici (1930) suggested that nasals may be devoiced in certain consonant clusters in Romanian (e.g. $/ \mathrm{m} /$ in /basm/ 'fairy-tale'). The phonetic literature has shown that many segments are articulated with greater strength at higher levels of prosodic boundaries (e.g. Intonational Phrase boundaries vs. word boundaries; see for example Keating et al. 2003 and Byrd et al. 2006), and this may be an influence on devoicing in Romanian. Using acoustic, aerodynamic and ultrasound data, we investigate the roles of prosodic boundaries, syllable structure, low-level phonetic assimilation and phonetic-level paradigm uniformity (Steriade 2000) in creating these devoiced nasals. We argue that several of these effects together cause these cross-linguistically unusual sounds. This paper serves three purposes. First, it investigates the distinction of sound patterns into phonetics vs. phonology. Second, it investigates prosodic domain boundaries in a new segment type. Third, it provides phonetic documentation of allophonic nasal devoicing, a phenomenon that has not been widely studied experimentally, in an understudied language. Because prosodic boundary strengthening has considerable detail to how it occurs in various segments, we will briefly review the literature on it before turning to the topic of nasal devoicing.

\subsection{Prosodic boundary levels and articulatory strengthening}

Several research groups have shown that speakers articulate sounds differently when they occur near a prosodic boundary, with consonant articulations strongest at utterance-level boundaries, followed by Intonational Phrase boundaries, then by word or syllable boundaries. The clearest effects are found for duration (lengthening of the consonants) and 
electro-palatograph (EPG) measures of strength of articulation contact (Fougeron \& Keating 1997, Keating et al. 2003, Keating 2006). Some vowels are also produced more peripherally to the vowel space, as well as being lengthened, at prosodic boundaries (Tabain 2003a, b, Cho 2005, Tabain \& Perrier 2005). Effects of prosodic boundaries are less clear when measured by articulograph as tongue displacement (Keating 2006). Overall, there is substantial evidence for articulatory strengthening as well as the more obvious lengthening. However, the specific effects, for example pre- $v s$. post-boundary, which measures and which vowels and consonants, are highly variable across speakers, levels of boundary and studies.

Related literature (Byrd \& Saltzmann 2003, Byrd et al. 2005, Byrd et al. 2006, Byrd \& Choi 2010) investigates slowing of gestures near prosodic boundaries, and argues that this can be modelled as a prosodic gesture, adding prosody to the framework of Articulatory Phonology (Browman \& Goldstein 1992). Prosodic boundary strengthening may slow gestures more for consonant clusters in coda position (Byrd \& Choi 2010), but lengthening of single consonants in coda and onset position may be equal (Byrd et al. 2005). Most importantly for the current work, Byrd \& Choi (2010) find that word-final consonant clusters show less gestural overlap at higher-level prosodic boundaries. That is, a CC\# cluster has less gestural overlap if the word is utterance-final than if it is IP-final, or is not at any phrasal boundary. Bombien et al. (2007) show the same (lesser overlap at higher boundaries) for onset \#CC clusters. Tiede et al. (2007) also provide some information about gestural overlap in clusters.

Byrd \& Choi (2010) show that consonant clusters in syllable codas allow more overlap among their gestures than clusters in onset. They also find that clusters split across a word boundary show similar degrees of gestural overlap to clusters in a word onset when the word boundary is at a lowlevel phrasal boundary, but if a strong prosodic boundary (especially an utterance boundary) occurs at the word boundary, clusters split across the boundary show far less overlap. Chitoran et al. (2002) show for Georgian, however, that clusters spanning a syllable boundary (word-medially) have more overlap than those entirely within a syllable onset.

Krakow $(1993,1999)$ investigates boundary effects on degree of nasalisation. Krakow manipulates the position of a nasal relative to syllable and word boundaries, in sets such as hoe me, home E, home Lee, homely. She finds that coda nasals show far earlier velic lowering than onset nasals. She also finds that nasals before a word boundary and a following vowel, e.g. in home $E$, do not resyllabify, but rather behave as coda nasals. Finally, some items show variation even within a speaker between coda and onset nasalisation patterns. These results show that both syllable and word boundaries affect timing of nasalisation in English.

\subsection{Phonetics of voiceless or devoiced nasals}

Voiceless nasals, at least those that contrast with voiced nasals, are crosslinguistically rare (Maddieson 1984a, Ohala \& Ohala 1993, Ladefoged \& 


\section{Benjamin V. Tucker and Natasha Warner}

Maddieson 1996, Jessen \& Pétursson 1998). A search of the UPSID database shows 24 of 317 languages as having distinctive voiceless nasals (Botma 2004). Devoiced nasals may occur allophonically in many more languages, but simply not be noted. For example, it seems likely that an utterance-final nasal could be at least partly voiceless in English and possibly in many other languages. However, while other languages may have some devoicing at the boundaries of nasals, the absence of voicing in the Romanian case is quite perceptually noticeable. The Romanian case sounds much more extreme than the small amount of devoicing one might be able to measure in English, for example. The Romanian nasals are allophonically devoiced, and do not contrast with voiced nasals. However, what phonetic documentation has been done on non-voiced nasals has been on contrastive voiceless nasals, so we will review what is known about this segment type.

Voiceless nasals in Burmese end with a voiced portion, perhaps because acoustic cues to place of articulation during a completely voiceless nasal are very limited (Ohala 1975, Dantsuji 1986; cf. also Maddieson 1984b). The same has been shown for Icelandic voiceless nasals (Jessen \& Pétursson 1998). Unlike Burmese and Icelandic, Angamese has distinctive voiceless nasals without any final voiced part (Bhaskararao \& Ladefoged 1991, Blankenship et al. 1993, Ladefoged \& Maddieson 1996), and this literature states that they are entirely voiceless with an aspirated release. However, acoustic data in some of this same work show a voiced portion at the beginning rather than the end of the nasal, even though the aerodynamic data indicate an absence of voicing. Bhaskararao \& Ladefoged (1991) mention that voicing from a preceding frame-sentence vowel sometimes continues for a few periods after oral closure, thus into the nasal. It is not clear to what extent a voiced portion at the beginning of these nasals is typical, or would occur utterance-initially.

\subsection{Background on Romanian devoiced nasals}

Petrovici (1930) and Vasiliu (1965) claim that in Romanian, nasals can be devoiced in particular environments. Petrovici (1930), in early instrumental phonetic work on one speaker, recorded oral and nasal airflow using a nasal olive and kymograph for four repetitions each of the words /basm/ 'fairy-tale' and /basmul/ 'the fairy-tale'. He found that in /basm/, the nasal was devoiced completely in one repetition and partially in the other three repetitions. The four repetitions of /basmul/ all had a fully voiced $/ \mathrm{m} /$. While this is the extent of Petrovici's data on this topic, because of the technological limitations of the time, it does provide excellent evidence of the phenomenon in Romanian.

Vasiliu (1965) cites Petrovici's work as well as his own native intuitions, but no new phonetic evidence, to support a claim that any nasal in second position of a word-final cluster in Romanian is partially devoiced (e.g. / N/ $\left.\rightarrow\left[\mathrm{N}_{0}\right] / \mathrm{C}_{-} \#\right)$. He then applies this rule categorically throughout his phonological analysis of Romanian and extends it to all coda clusters with 
/1/ in second position (e.g. /zvirl/ 'I fling'). Thus Vasiliu makes Petrovici's specific finding a much broader claim about Romanian phonology, with little phonetic evidence. We know of no other instrumental investigation of this phenomenon, although there has been some other phonetic work on Romanian (e.g. Avram 1991, Chitoran 2001, 2002, Marin 2007).

More general final devoicing, such as Dutch /wat/ 'what' and /wad/ 'mudflat' surfacing as [wat], has been well studied in German, Dutch, Catalan, Polish and other languages. It constitutes the best known case of incomplete neutralisation (Warner et al. 2004 and references cited therein). Romanian does not have final devoicing of this general type. In English, onset sonorants are known to devoice following voiceless obstruents (e.g. plea [pli]). Tsuchida et al. (2000) argue that there are both phonetic and phonological contributions to this process. Aerodynamic work by Westbury \& Keating (1986) has specifically modelled devoicing in obstruents. They find that the most phonetically natural type of obstruents based on aerodynamics is voiceless for initial and final positions, and voiced for medial positions. However, they also find that many languages do not use this distribution, instead keeping the phonetic realisation of a phoneme relatively constant across environments. Although Romanian may have some very slight devoicing effects in obstruents that have gone unnoticed, it does not have any other known assimilatory devoicing or final devoicing in obstruents, other than the devoicing in clusters studied here (Vasiliu 1965). Vasiliu (1965) does describe devoicing of final vowels. The studies mentioned here contribute knowledge of how phonetics and phonology interact in other types of devoicing, but do not transfer directly to the Romanian cluster case.

\subsection{The current study}

To determine how phonetic and phonological factors contribute to the realisation of Romanian nasals, we first need modern instrumental documentation of the relevant nasals. The first question is whether nasals are in fact devoiced in the claimed clusters, but not when the cluster is split across a syllable boundary. Second, one should confirm that these nasals are devoiced rather than outright deleted. Third, Petrovici (1930) investigated nasal devoicing in isolated words, so all the cases of devoicing he found were at an utterance boundary. This suggests that devoicing, if it exists, might be affected by the strength of the boundary at which the cluster occurs or by the transition to voicelessness at the end of an utterance.

We test the clusters $/ \mathrm{sm} /$ and $/ \mathrm{mn} /$ in a variety of phonological environments: utterance-final, word-final before a word beginning with a voiced or voiceless segment and word-medial. For example, /basm/ appears utterance-finally in one condition, but within a sentence in others, e.g. before /o dat $\Lambda$ / 'once' or / puternik/ 'powerfully'. /turismul/ 'tourismthe' provides a word-medial, syllable-boundary spanning, condition. By comparing the word-medial and word-final environments, we can test for 


\section{Benjamin V. Tucker and Natasha Warner}

the effect of syllable structure the early work suggests. A comparison of word-final nasals before voiced-initial and voiceless-initial words can test for effects of low-level phonetic assimilation to surrounding voiceless sounds while holding boundary strength constant, and can also test for phonetic paradigm uniformity (Steriade 2000), if devoicing seems to be transferred from one environment to another. Comparison of the $/ \mathrm{sm} /$ to the $/ \mathrm{mn} /$ cluster (e.g. / basm/ to /somn/ 'sleep') allows a further test of phonetic assimilation, because of the voiceless $/ \mathrm{s} /$ in the former cluster. Furthermore, by comparing the word-final environment before a voiceless-initial word to the utterance-final environment, we can test for greater devoicing at utterance boundaries than word boundaries, a prosodic domain effect. Finally, by separating effects of phonetic assimilation, paradigm uniformity, syllable structure and prosodic domains, we can examine what is phonetic and what is phonological about the production of these unusual clusters.

Romanian nasal devoicing is particularly suitable for such an investigation, because the devoiced nasals occur in clusters in Romanian and these clusters require coordination of a great many gestures. Previous work has been on phonemically voiceless nasals in other languages, primarily on word-initial prevocalic nasals. Romanian offers an opportunity for documentation of positional, allophonic nasal devoicing, which has not been studied in phonetic detail. Devoiced nasals, because they often have low amplitude, lend themselves well to study through a combination of acoustic and articulatory methods. In this work, we use acoustic, ultrasound and aerodynamic data (Experiments 1, 2 and 3 respectively) for a broad approach to documentation of these sounds.

\section{Experiment 1: acoustics}

Experiment 1a examines the $/ \mathrm{sm} /$ sequence and $1 \mathrm{~b}$ examines the $/ \mathrm{mn} /$ sequence. These are the only consonant-nasal clusters that occur often enough word-finally in the Romanian lexicon to provide sufficient items for statistical analysis.

\subsection{Experiment 1a}

\subsubsection{Methods.}

Subjects. Eight native Romanian speakers between the ages of 18 and 60 participated in the experiment. One speaker was excluded from analysis because it was later determined that this speaker had a speech disorder. None of the seven remaining speakers reported any kind of speech or hearing disorder. Two speakers were living in the United States, but had lived in Romania at least until the end of high school. The remaining five speakers were recorded in Romania, and had lived most or all of their lives there. Two of these speakers were monolingual, three spoke English and one also spoke Russian, but their L2s were learned in school or later. 


\begin{tabular}{|c|c|c|}
\hline code & frame sentence & environment \\
\hline —\#\# & /ea a spus__' & utterance-final \\
\hline — \#V & $\begin{array}{l}\text { /ea a spus__o dat } \Lambda / \\
\text { 'She said__one time.' }\end{array}$ & word-final prevocalic \\
\hline$-^{\# \mathrm{~d}}$ & $\begin{array}{l}\text { /ea a spus__de dow } \text { or }^{\mathrm{j}} / \\
\text { 'She said__two times.' }\end{array}$ & word-final pre-voiced stop \\
\hline —\#p & $\begin{array}{l}\text { /ea a spus__ puternik/ } \\
\text { 'She said__ powerfully.' }\end{array}$ & word-final pre-voiceless stop \\
\hline
\end{tabular}

\section{Table I}

Frame sentences, description of phonetic environments and codes used to abbreviate the environments. The word-medial environment $\mathrm{V}-\mathrm{V}$ is defined by the target words rather than the frame sentence.

Six speakers were male and one was female. Speakers were from diverse areas within Romania (three from Muntenia, two from the Ardeal region and two from the Moldovan region). Dialect was not controlled, and we are unaware of any dialectal differences in the nasal clusters in question.

Materials. Target words (see Appendix 1) were selected using a Romanian dictionary (Academia RSR 1996). Eight words contained a word-final $/ \mathrm{sm} /$ cluster (e.g. / Jovinism/ 'chauvinism'). Two additional words contained $/ \mathrm{sm} /$ in word-medial position (e.g. /turismul/), both with the suffix /-ul/ 'the'. The $/ \mathrm{sm} /$ sequence is not very common morphemeinternally; however, it occurs frequently as a suffix, and words like /basm/ demonstrate that it can occur within stems as well. Frame sentences enabled the manipulation of following segmental context (Table I). Both word-medial cluster items and word-final cluster items were placed in the frame sentences, meaning that the word-medial items have four repetitions of each item (in different frame sentences) by each speaker.

Procedures and measurements. Speakers read the list of ten words in each of four frame sentences, blocked by frame sentence. The speakers first read through the list to familiarise themselves with the items. Recordings in the U.S. were made at the University of Arizona in a soundattenuated booth, while recordings in Romania were made in relatively quiet rooms made available by subjects. Within the booth, subjects sat in front of a microphone on a desk stand. The subjects in Romania held the microphone, keeping their mouths as close to it as possible. Recordings were made using an Alesis CD recorder in the U.S. or a portable DAT recorder in Romania (from which recordings were redigitised), both at a sampling rate of $44,100 \mathrm{~Hz}$.

Recordings were analysed using Praat (Boersma \& Weenink 2005). Measurements (see Fig. 1) were made of the durations of the previous vowel, the fricative $/ \mathrm{s} /$, the nearly silent gap between fricative and nasal (if possible; see below), and the voiced part of the nasal (if any). Vowel durations were measured from the onset to the offset of F2. Fricative 
(a)

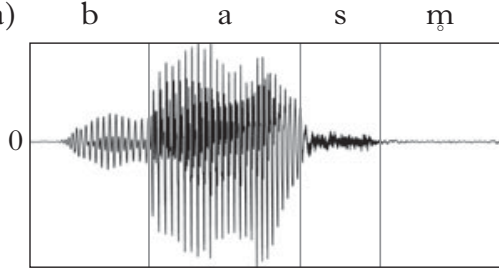

vowel fric

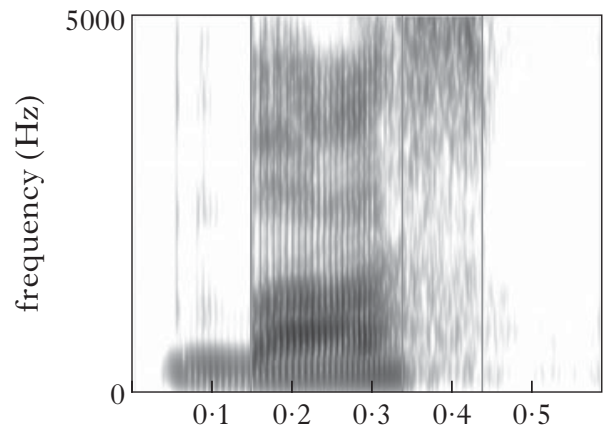

(b)
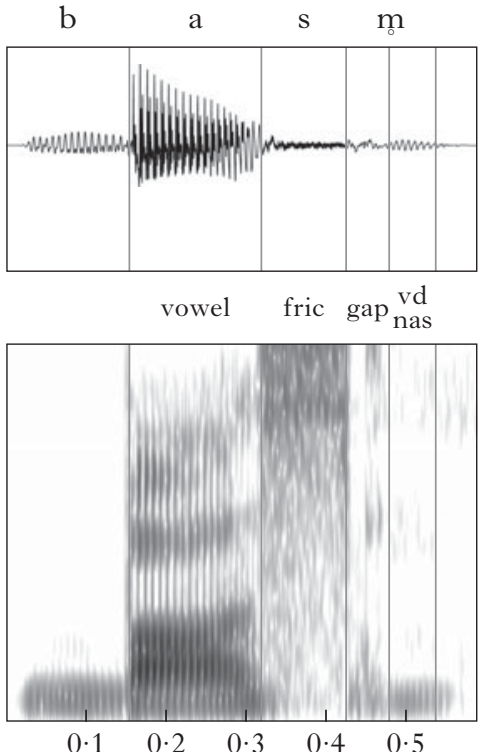

time (sec)

Figure 1

Waveform and spectrogram for two tokens of /basm/ 'fairy-tale' in utterance-final environment, (a) without (Speaker 1) and (b) with (Speaker 5) a voiced nasal portion. Vertical lines indicate the boundaries between individual measurements.

durations were measured from the onset to the offset of high-frequency frication noise. All tokens were classified as either lacking (Fig. 1a) or having (Fig. 1b) a voiced nasal portion. The gap duration was measured only in tokens with a voiced nasal portion, because the gap duration was defined as the duration from the end of frication to the onset of voicing (Fig. 1b). Duration of nasal voicing was measured from the onset to the offset of periodic vibration in the waveform. Total nasal duration could not be measured, because the voiceless portion of a nasal produces too little acoustic trace to be reliably distinguishable from any potential pauses or silences.

In Fig. 1a, the expected location of $/ \mathrm{m} /$ is marked, but there is no acoustic material indicating it, other than low-amplitude noise that could be the trailing off of the [s]. Even in languages without voiceless or devoiced nasals, a brief silent gap often occurs between an [s] and the onset of voicing after it, because the high oral air pressure for the [s] must dissipate before voicing can begin (cf. Stevens 1998). The gaps measured in Romanian could thus be the gap caused by slight overlap of the fricative and nasal, rather than reflecting speakers' intentional production of (partially) devoiced nasals. We will return to this issue below. 


\begin{tabular}{|c|c|c|c|c|c|}
\hline & _\#\# & _ \#V & - \#d & — \#p & $\mathrm{V}_{-} \mathrm{V}$ \\
\hline Preceding V duration (ms) & 168 & 134 & 132 & 125 & 111 \\
\hline Preceding /s/ duration (ms) & 103 & 89 & 84 & 83 & 78 \\
\hline $\begin{array}{l}\text { Count of nasals with voiced part } \\
\text { present }\end{array}$ & 13 & 20 & 14 & 11 & 56 \\
\hline $\begin{array}{l}\text { Duration of voiced part of nasal when } \\
\text { present (ms) }\end{array}$ & 64 & 57 & 63 & 85 & 58 \\
\hline Gap duration (ms) & 40 & 65 & 73 & 81 & 50 \\
\hline
\end{tabular}

\section{Table II}

Results of Experiment 1A (acoustic data for / sm/ clusters), by measure and environment. For nasals with a voiced portion, all counts are out of 56 tokens.

Predictions. If Petrovici's (1930) data are representative, we predict that at least in utterance-final environment, the nasal of the $/ \mathrm{sm} /$ cluster will be partially or fully voiceless in many tokens, and that word-medial (split across syllable boundary) clusters will not show devoicing. If prosodic domains play a substantial role in this devoicing, we expect greater or more frequent devoicing in the utterance-final environment than the other word-final environments. However, if devoicing is primarily determined by low-level phonetic assimilation to surrounding voiceless sounds, we expect to find greater devoicing in both utterancefinal and word-final pre-voiceless environments than elsewhere. That is, if the word-final pre-voiceless condition (_\#p, e.g. / basm puternik/ 'fairy-tale powerfully') differs from the utterance-final condition ( _ \#\#), this supports a role for prosodic domains. However, if the word-final prevoiceless condition (_\#p) patterns with utterance-final position and differs from other word-final positions, this supports a role for phonetic assimilation. If syllable structure is the only conditioning factor for devoicing, as Vasiliu (1965) implies, then we would expect devoicing to be equal in all word-final and utterance-final environments, and to differ from full voicing in word-medial environment.

2.1.2 Results. $74 \cdot 3 \%$ of all word-final $/ \mathrm{sm} /$ tokens lacked any voiced nasal at all following the [s] (Fig. 1a). In the other $25.7 \%$ of tokens (Fig. 1b), a silent gap occurred between the /s/ and the voiced part of the $/ \mathrm{m} /$. Results appear in Table II. For each measure, unless otherwise noted, an ANOVA with Phonetic Environment as the only factor (withinsubjects, with data first averaged over items) was used. Preceding vowel duration $(\mathrm{F}(4,24)=15 \cdot 859, \mathrm{p}<0 \cdot 001)$ and duration of the $/ \mathrm{s} /(\mathrm{F}(4,24)=$ $4.815, \mathrm{p}<0 \cdot 001)$ both showed significant effects of phonetic environment, with the longest durations for utterance-final environment and the shortest for word-medial environment. This suggests that final lengthening is strongest at the utterance boundary. Table II includes counts of how many tokens had a voiced nasal portion, and a chi-squared analysis (with 


\section{Benjamin V. Tucker and Natasha Warner}

data pooled over subjects) verifies that the environments did differ in this as well $\left(\chi^{2}(4, n=282)=106 \cdot 09, \mathrm{p}<0 \cdot 05\right)$. This is expected, because all word-medial tokens (which should not devoice) have a voiced portion. Excluding the word-medial environment, presence of a voiced portion is equally likely in all word-final environments $\left(\chi^{2}(3, n=226)=3.93\right.$, $\mathrm{p}>0.05)$.

Table II includes data on duration of the voiced portion of the nasal (when present) and duration of the silent gap between the end of frication and onset of any nasal voicing. Some speakers had no tokens with a voiced nasal portion at all in some environments, leaving too little data on these measures for reliable statistical analysis. What is primarily of interest is that the voiced portion of the nasal was rather short $(57-85 \mathrm{~ms})$, and that the voiceless gap between frication and onset of nasal voicing was rather long (40-81 ms average by condition), relative to the small quantity of voicelessness after frication ceases that one might expect if the $/ \mathrm{s} /$ and $/ \mathrm{m} /$ simply overlapped slightly at their boundary.

2.1.3 Discussion. In approximately three-quarters of all non-medial $/ \mathrm{sm} /$ tokens, $/ \mathrm{m} /$ is completely devoiced, with no voiced portion of the nasal whatsoever. Thus the initial descriptive question of whether Romanian nasals in the $/ \mathrm{sm} /$ cluster devoice is answered: the early report of devoicing (Petrovici 1930) is confirmed. The count data show that there is a categorical difference between word-medial environment (where no token is fully devoiced) and all word-final environments, and also shows that there is no difference among word-final environments in how often $/ \mathrm{m} /$ is completely devoiced. This suggests a phonological process based on syllable structure similar to the one proposed by Vasiliu (1965), although a variable one, since not all word-final tokens are fully devoiced. When the cluster is in coda position, the nasal is usually fully devoiced, but when the cluster is split across a syllable boundary so that the nasal itself is in onset position, there is no devoicing. ${ }^{1}$ However, because of the low amplitude of a voiceless $/ \mathrm{m} /$, it is still possible that the completely voiceless tokens are deleted rather than devoiced.

Because there are few tokens with partial voicing in the word-final environments, we do not attempt to interpret differences among wordfinal environments in duration of the voiced part of the nasal or duration of the silent gap before voicing. However, the fact that the voiced part of the word-final nasals is rather short for a nasal, and that the silent gaps before the onset of nasal voicing are rather long, suggests that even those word-final tokens that do have a voiced portion of the nasal have partial devoicing, constituting the gap, as in Fig. 1b.

In sum, the acoustic results on the $/ \mathrm{sm} /$ cluster show that there is variable devoicing of the $/ \mathrm{m} /$ in all word-final environments, with complete devoicing the most common and partial devoicing in the remaining

1 Like Byrd \& Choi (2010), we refer to word-final clusters as being in coda position, even if a vowel-initial word follows, so that resyllabification could be possible. 
tokens. This demonstrates two distinct types of gradience in application of devoicing: devoicing is gradient in whether it happens (happening in some tokens and not in others), and in to what extent it happens (full or partial devoicing in a given token). The results also show that this devoicing phenomenon is conditioned by syllable structure, applying to coda clusters, not those split across a syllable boundary. However, it is possible that low-level phonetic assimilation to the $/ \mathrm{s} /$ could be conditioning this devoicing, and the data from Experiment 1a also cannot rule out the possibility that the nasal is deleted rather than devoiced in the tokens with no voiced nasal portion. Experiment $1 \mathrm{~b}$ addresses the question of deletion. By providing data on a comparison cluster with no voiceless segment, $/ \mathrm{mn} /$, it also allows us to separate out the effect of assimilation to the voiceless $/ \mathrm{s} /$.

\subsection{Experiment $1 b$}

Experiment $1 \mathrm{~b}$ is largely similar to Experiment $1 \mathrm{a}$, except that it uses $/ \mathrm{mn} /$ rather than $/ \mathrm{sm} /$ clusters. This experiment also introduces a comparison to a single $/ \mathrm{m} /$ or $/ \mathrm{n} /$ segment not in clusters (e.g. /baton/ 'stick'). Vasiliu (1965) predicts that word-final $/ \mathrm{mn} /$ would have a devoiced $/ \mathrm{n} /$, but Petrovici (1930) gave no instrumental data on this cluster. The difficulty in analysing $/ \mathrm{mn} /$ lies in determining when $/ \mathrm{m} /$ ends and $/ \mathrm{n} /$ begins, which makes it difficult to determine if the second segment is devoiced. However, duration and comparison to the single nasal condition can be used to determine indirectly whether there is a devoiced nasal and whether there are indeed two segments (thus devoicing rather than deletion).

The predictions in this experiment partly parallel those in the first experiment. If Vasiliu's (1965) claim about syllable structure is correct, we expect to find devoicing in $/ \mathrm{mn} /$ word-final clusters, but not in wordmedial clusters. If assimilation to voiceless segments is a cause of the devoicing, we expect to find less devoicing in this experiment than in the /sm/ clusters above. Predictions regarding prosodic domain effects and phonetic assimilation to the following sound remain the same. However, additionally, if there is devoicing in $/ \mathrm{mn} /$ even before a voiced onset word $(\ldots \# \mathrm{~d}$ or $\ldots \mathrm{V})$, this would indicate a paradigm-uniformity effect (Steriade $20 \overline{00}$ ), in that devoicing is transferred from environments where it can occur as assimilation to a following voiceless segment to environments lacking any voiceless segments. Furthermore, in comparing the $/ \mathrm{mn} /$ nasal cluster to the single $/ \mathrm{m} /$ or $/ \mathrm{n} /$, if there is devoicing rather than deletion, clusters should be longer than single nasal segments.

\subsubsection{Methods}

Subjects. The subjects were the same speakers as in Experiment 1a, with the same exclusion.

Materials. The materials (Appendix 2) contain an $/ \mathrm{mn} /$ cluster wordfinally (e.g. /somn/ 'sleep'; eight items), an $/ \mathrm{mn} /$ cluster word-medially (e.g. /temnitss 'black hole'; seven items), or a single $/ \mathrm{m} /$ or $/ \mathrm{n} /$ 


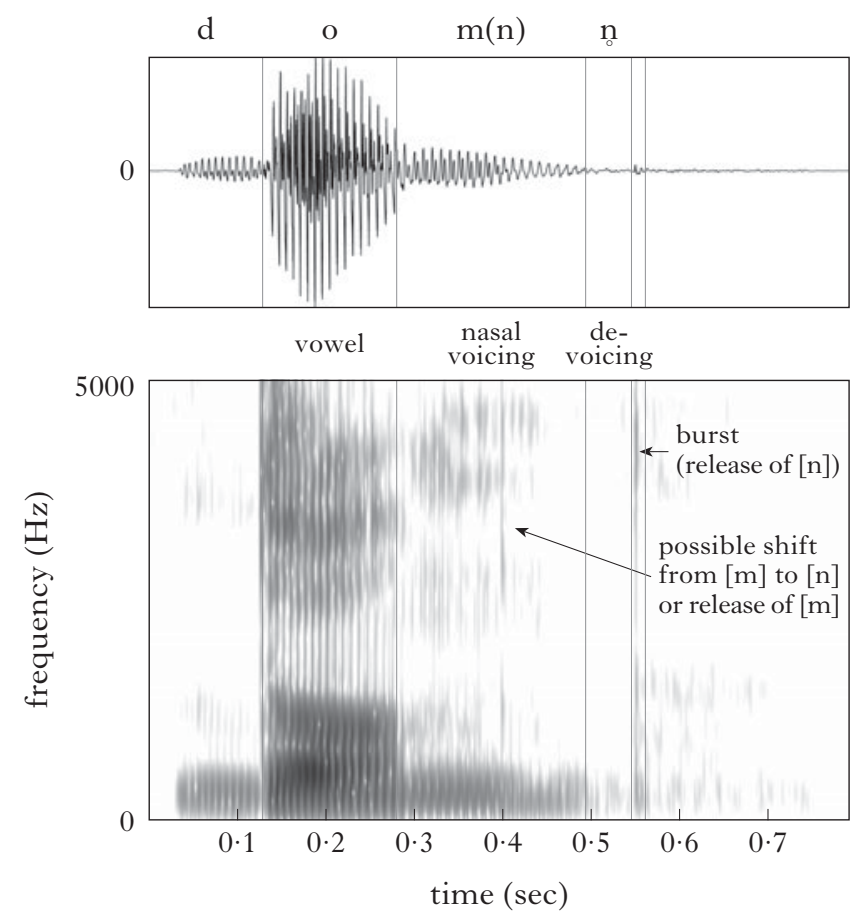

Figure 2

Waveform and spectrogram of /domn/ 'Lord, sir' in utterance-final environment. Vertical lines indicate the boundaries between individual measurements.

word-finally (e.g. /lakom/ 'greedy'; eight items). After data collection a gap was found in the distribution of the nasals in the word-medial environment: data had not been collected for the single $/ \mathrm{m} /$ or $/ \mathrm{n} /$ wordmedial $(\mathrm{V}-\mathrm{V})$ environment. In the results below, this condition is left blank. The single $/ \mathrm{m} /$ or $/ \mathrm{n} /$ condition introduces an additional comparison (single nasal $v s$. double nasal cluster) that was not possible for $/ \mathrm{sm} /$ in Experiment 1a. The frame sentences were the same as in Experiment 1a (utterance-final, preceding a vowel, preceding a voiced consonant and preceding a voiceless consonant).

Procedures. Procedures were the same as in Experiment 1a, except for changes in what measurements were possible. The two sets of words, blocked by cluster, were recorded in the same recording session. For all tokens, the duration was measured for the vowel preceding the nasal sequence and the total duration of nasal voicing (total for $/ \mathrm{mn} /$ or single $/ \mathrm{m} /$ or $/ \mathrm{n} /$ ) (Fig. 2). A burst-like, sudden, broadband noise occurred following the $/ \mathrm{mn} /$ cluster in the utterance-final condition and sometimes in other environments. This appears to be a barely audible release of the voiceless nasal. The duration from the offset of voicing to the onset of this nasal 
burst (when present) was measured, and was assumed to be the voiceless portion of the nasal. Tokens were also classified by whether they contained such a nasal burst or not. If there was no such nasal burst, then any voiceless portion before the following word was considered a pause between the words or part of the following word's initial segment rather than a devoiced nasal portion, in order to avoid exaggerating the frequency of devoicing. For the $\# \mathrm{~d}$ environment, if voicing continued throughout the nasal into the $/ \mathrm{d} /$, the beginning of the burst of the $/ \mathrm{d} /$ was taken to be the end of the nasal sequence, as there was no visible shift from nasal voicing to stop closure voicing. Some tokens (mostly produced by Speaker 1) showed a frequency shift during the voiced nasal at the beginning of the [n] closure, or a small burst-like transient showing the labial release for [m] (Fig. 2). However, these were generally too unclear to be measured, and were too infrequent for cross-speaker analysis.

2.2.2 Results. Measurements were averaged over items. For each measure, an ANOVA was conducted with the within-subjects independent variables Phonetic Environment (with the four conditions _\#\#, _ $\# \mathrm{~V}, \ldots \mathrm{d}, \ldots \mathrm{\# p}$ ) and Nasal Sequence Type (single vs. cluster). The word-medial environment was excluded from these ANOVAs, because of the absence of single-nasal word-medial data.

The duration data, as well as counts of how many tokens have a nasal burst, are shown in Table III. Preceding vowel duration was greatest for utterance-final environment and least for word-medial environment, ${ }^{2}$ with a significant main effect of Environment $(F(3,18)=8.060, p<0.005)$, no effect of Nasal Sequence Type $(\mathrm{F}<1)$ and no interaction $(\mathrm{F}(3,18)=2 \cdot 945$, $\mathrm{p}=0.061)$. Environment affected duration of the voiced portion of the nasal $(F(3,18)=5 \cdot 644, p<0 \cdot 05)$, as did Nasal Sequence Type $(F(1,6)=$ $58.914, \mathrm{p}<0.01)$, with greater duration for clusters than single nasals), but the interaction was not significant $(\mathrm{F}(3,18)=2 \cdot 729, \mathrm{p}>0 \cdot 05) .{ }^{3}$ The counts of number of tokens with a nasal burst showed some differences by phonetic environment, with the utterance-final environment having more nasal bursts than other environments $\left(\chi^{2}(3, n=224)=40 \cdot 875, \mathrm{p}<0 \cdot 0001\right)$, comparing among only the four word-final environments; clusters only). The word-medial nasal clusters had no discernable nasal bursts at all (hence their exclusion from the chi-squared test). Table III also includes the durations from the offset of voicing to the onset of the nasal burst (if present), hence the duration of the voiceless portion of the nasal. No statistics were conducted for this measure, because it was available for a

${ }^{2}$ However, word-medial environment is not included in statistical testing here, to allow the two-factor design. It has the shortest duration.

3 One might think that only the single $/ \mathrm{n} /$ data should be compared to the cluster data, since the presumably devoiced segment of the cluster is the $/ \mathrm{n} /$ of the cluster. Post hoc analysis shows that single $/ \mathrm{m} /$ was significantly longer than single $/ \mathrm{n} /(\mathrm{F}(1,5)=$ $69.670, \mathrm{p}<0.05)$, so using only $/ \mathrm{n} /$ rather than both single $/ \mathrm{n} /$ and $/ \mathrm{m} /$ as the comparison group would only increase the size of the difference between single and cluster nasals. 


\begin{tabular}{|c|c|c|c|c|c|c|}
\hline & & & & & \\
\hline & & _\#\# & _\#V & $\ldots$ & —\#p & $\mathrm{V} \_\mathrm{V}$ \\
\hline \multirow[t]{3}{*}{ Preceding V duration (ms) } & $/ \mathrm{mn} /$ & 132 & 120 & 115 & 103 & 111 \\
\hline & $/ \mathrm{m} /$ & 148 & 118 & 113 & 98 & \\
\hline & /n/ & 135 & 114 & 113 & 98 & \\
\hline \multirow{3}{*}{$\begin{array}{l}\text { Duration of voiced part of nasal } \\
(\mathrm{ms})\end{array}$} & $/ \mathrm{mn} /$ & 156 & 140 & 170 & 155 & 134 \\
\hline & $/ \mathrm{m} /$ & 135 & 106 & 125 & 111 & \\
\hline & $/ \mathrm{n} /$ & 119 & 78 & 98 & 102 & \\
\hline \multirow{3}{*}{$\begin{array}{l}\text { Count of tokens with a nasal } \\
\text { burst ( } 56 \text { possible per cell) }\end{array}$} & $/ \mathrm{mn} /$ & 42 & 23 & 16 & 11 & 0 \\
\hline & $/ \mathrm{m} /$ & 11 & 0 & 0 & 0 & \\
\hline & $\mid \mathrm{n} /$ & 12 & & 1 & 1 & \\
\hline \multirow{3}{*}{$\begin{array}{l}\text { Duration from end of voiced } \\
\text { nasal to onset of nasal burst, } \\
\text { if any (ms) }\end{array}$} & & 45 & 47 & 39 & 28 & $\begin{array}{c}\text { no } \\
\text { tokens }\end{array}$ \\
\hline & $/ \mathrm{m} /$ & 51 & $\begin{array}{c}\text { no } \\
\text { tokens }\end{array}$ & $\begin{array}{c}\text { no } \\
\text { tokens }\end{array}$ & $\begin{array}{l}\text { no } \\
\text { tokens }\end{array}$ & \\
\hline & $/ \mathrm{n} /$ & 47 & $\begin{array}{l}\text { no } \\
\text { tokens }\end{array}$ & 49 & $\begin{array}{l}\text { no } \\
\text { tokens }\end{array}$ & \\
\hline
\end{tabular}

Table III

Summary of results from Experiment 1B (acoustic data for $/ \mathrm{mn} /$ cluster) divided by measure, environment and type of nasal sequence (cluster $/ \mathrm{mn} / v s$. single $/ \mathrm{m} /$ or $/ \mathrm{n} /$ ). Single $/ \mathrm{m} /$ and $/ \mathrm{n} /$ were not recorded in the medial $\mathrm{V}$ _ V environment.

limited set of tokens, but it is clear from the averages $(28-50 \mathrm{~ms})$ that there was a substantial voiceless period during many tokens, ending in a release for the nasal consonant. (Although one could perhaps measure duration of voicelessness even without a visible nasal release, speakers could pause between words, so we measured the voiceless portion only when it was delineated by the nasal release.)

2.2.3 Discussion. The results of Experiment $1 \mathrm{~b}$ indicate that $/ \mathrm{mn} /$ clusters are partially, but not fully, devoiced, and that some tokens of phrase-final singleton nasals also show some partial devoicing. One important result is that the duration of the voiced nasal portion is longer for the $/ \mathrm{mn} /$ clusters than for single $/ \mathrm{m} /$ or $/ \mathrm{n} /$. This rules out deletion as an alternative explanation for the devoicing phenomenon, because it shows that a cluster of two nasals contains more linguistic material than a single nasal segment. Furthermore, the fact that even the voiced part of the nasals is longer for the $/ \mathrm{mn} /$ clusters than for the single nasals allows us to conclude that $/ \mathrm{mn} /$ has partial, rather than complete, devoicing: if the final $/ \mathrm{n} /$ in the cluster were completely devoiced, there would be no reason for the cluster to have a longer voiced nasal duration than a single nasal.

Because the $/ \mathrm{mn} /$ data provide evidence of partial devoicing, while the most common realisation for $/ \mathrm{sm} /$ in Experiment 1a was complete 
devoicing, we can conclude that there is more devoicing in the $/ \mathrm{sm} /$ cluster than the $/ \mathrm{mn} /$ cluster. This suggests an influence of low-level phonetic assimilation: $/ \mathrm{sm} /$ shows more devoicing than $/ \mathrm{mn} /$ because of the voicelessness of $/ \mathrm{s} /$. However, devoicing is not entirely caused by assimilation: it occurs in $/ \mathrm{mn} /$ even when the following word begins voiced $(/ \mathrm{Vmn} \# \mathrm{~d} /$ and $/ \mathrm{Vmn} \# \mathrm{~V} /$ ). Devoicing in these environments, where there are no surrounding voiceless sounds at all, can be considered a case of paradigm uniformity affecting a relatively low-level aspect of realisation, as Steriade (2000) suggests for other alternations. The partial devoicing of the nasal is transferred from environments where the following voicelessness contributes to it ( $\mathrm{Vmn} \# \mathrm{p}$ and $\mathrm{Vmn} \# \#)$ to environments with no surrounding voicelessness, thus keeping a matched phonetic realisation across all forms of the word. We can conclude that several factors, varying in how phonetic vs. phonological they seem to be on various criteria, together cause Romanian nasal devoicing.

The argument that longer duration for the voiced portion of the nasal implies that there is partial devoicing, not full devoicing and not deletion, is an indirect one. The final nasal in $/ \mathrm{mn} /$ could instead be deleted, with compensatory lengthening of the first nasal. However, this interpretation is ruled out by the finding that a substantial proportion of $/ \mathrm{mn} /$ tokens in all word-final environments have a near-silent gap and then a small burstlike release for the second nasal. The limitation of these gaps and nasal bursts to word-final environments supports the finding from Experiment 1a that devoicing only occurs in word-final (coda) clusters.

The data on duration of the preceding vowel and duration of the voiced portion of the nasal show appropriate final lengthening, but do not show clear patterns among the various word-final environments. Furthermore, the nasal releases are important because of the fact that they occur in word-final but not medial position, but, unfortunately, differences in how often they occur among word-final environments cannot be used to draw conclusions about strength of devoicing. This is because the greater prevalence of nasal releases in utterance-final position may reflect masking of the nasal release by gestures of a following consonant or by greater amplitude of a following vowel, rather than an effect of boundary strength. Therefore, we do not draw conclusions among the word-final conditions based on this data.

Experiments $1 \mathrm{a}$ and $1 \mathrm{~b}$ together have shown that word-final $/ \mathrm{sm} /$ has complete devoicing in most tokens and partial devoicing in the rest, that word-final $/ \mathrm{mn} /$ has partial devoicing but not deletion and that devoicing in both clusters occurs in word-final (coda) position, but not when the cluster is split across syllables. However, the acoustic data provide only indirect evidence for some of these points, and these experiments have not clarified whether phonetic assimilation, prosodic domain strength or both influence how strong devoicing is in the various word-final environments. In the following experiments, we turn to articulatory methods to verify the conclusions of Experiments $1 \mathrm{a}$ and $1 \mathrm{~b}$ and to investigate the possibility of prosodic domain strength effects $v s$. assimilation. 


\section{Experiment 2: ultrasound}

Experiment 1 showed that the second segment in the $/ \mathrm{sm} /$ and $/ \mathrm{mn} /$ clusters is often devoiced to varying degrees, depending on the following environment. Although it was argued above, based on indirect acoustic evidence, that the nasal is devoiced rather than deleted, Experiment 1 does not explicitly show the articulatory gestures for the second segment of the $/ \mathrm{sm} /$ and $/ \mathrm{mn} /$ clusters. This is particularly relevant in the $/ \mathrm{mn} /$ cluster, where it could be argued that the $/ \mathrm{n} /$ is deleted and the $/ \mathrm{m} /$ compensatorily lengthened. Ultrasound in conjunction with video recording of the lips can provide convergent evidence.

\subsection{Methods}

Subjects. One native Romanian speaker was recorded for this experiment. The speaker was a male speaker who moved to the United States after completing high school, and was also a participant in Experiment 1.

Stimuli. The materials (see Appendix 3) used the same frame sentences and similar word lists to those in Experiments 1 and 3. Twelve $/ \mathrm{mn} /$ cluster items and six $/ \mathrm{sm} /$ cluster items were analysed in the _\#\#, \# \#d and _ \#V environments. In the _\#p environment, only eight $/ \mathrm{mn} /$ and three $/ \mathrm{sm} /$ items were analysed, because of a data-transfer error. This experiment did not include single $/ \mathrm{m} /$ or $/ \mathrm{n} /$ or word-medial clusters, as the primary purpose was to confirm that tokens in devoicing environment do have an oral closure for the nasal, not to compare devoicing to nondevoicing environments.

Procedure. The subject sat on a chair fixed to the ground, which also provided head support. A SonoSite TITAN ${ }^{\mathrm{TM}}$ ultrasound unit with a C-11/7-4 $11 \mathrm{~mm}$ broadband curved array transducer generated the ultrasound view. A Sony Mini-DV Digital Handycam generated the video view. The two video signals were combined using a Videonics MXProDV digital video mixer at a sampling rate of 33 frames per second. To obtain an ultrasound image of the speaker's tongue, a transducer covered with a small amount of gel was placed under the speaker's jaw, creating an image of the tongue as seen in Fig. 4. An arm attached to the base of the chair held the transducer in a fixed position. A video image of the profile of the speaker's face was also recorded (Fig. 4). The speaker put a spoonful of yogurt into his mouth; the image recorded while the speaker's mouth was filled with yogurt allows for a palate tracing. The palate tracing, superimposed over individual images, provides a reference for the tongue location. No corrections for head movement were made, but support for the speaker's head limited head movement. The audio channel was recorded for analysis together with the video. Once the speaker was comfortably seated in the chair with the equipment properly adjusted, the speaker read out the words in the frame sentences. 
Image 1

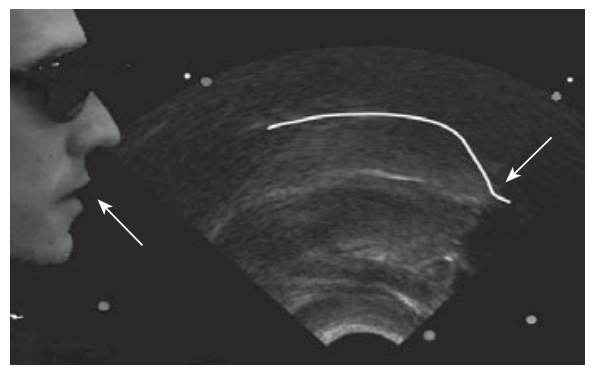

Image 2
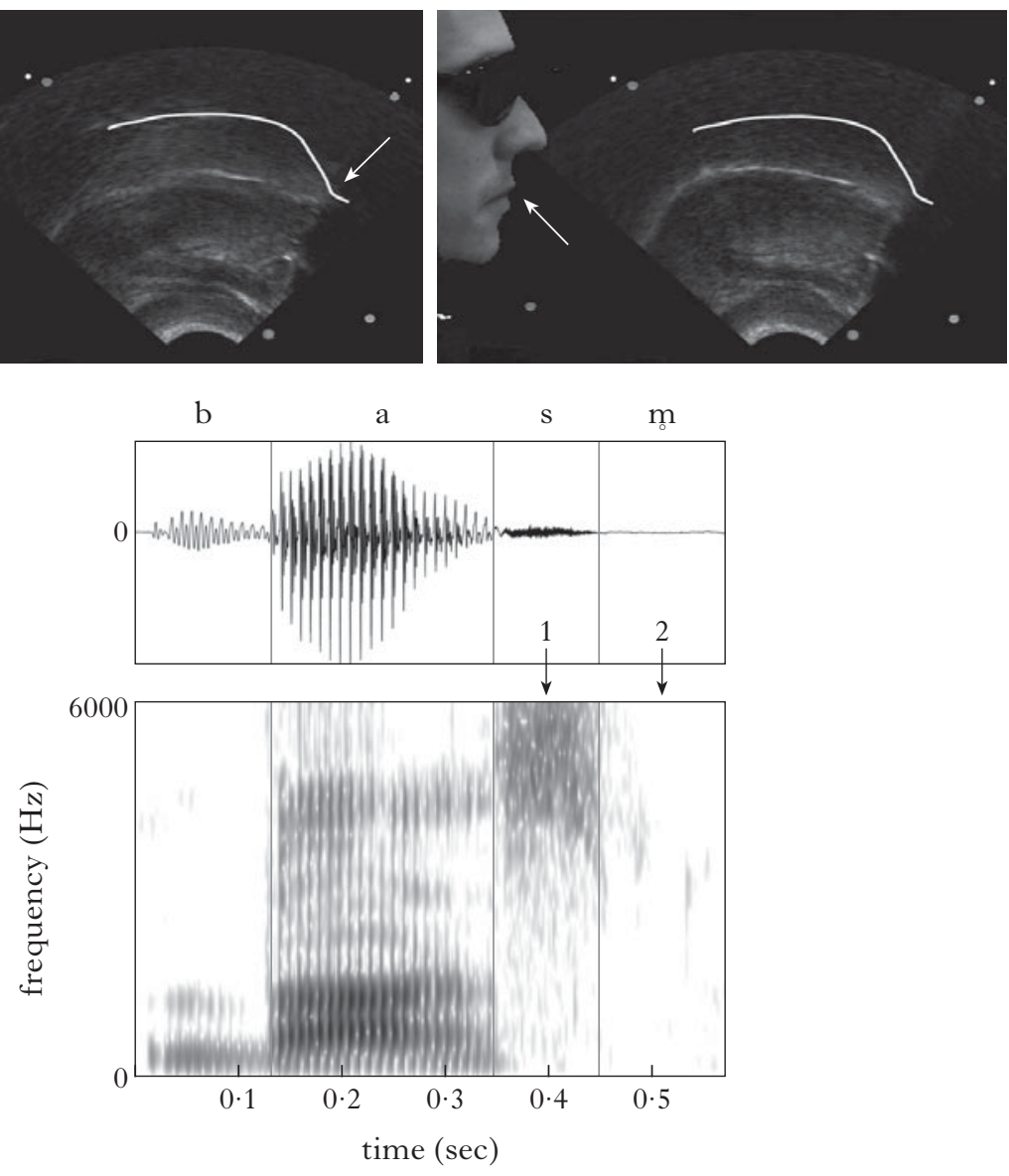

Figure 3

Two video/ultrasound images for / basm/ 'fairy-tale'. Image 1 shows alveolar closure for the $/ \mathrm{s} /$ (with no bilabial closure at that time). Image 2 shows bilabial closure for the $/ \mathrm{m} / \mathrm{a}$ few frames (between $66 \mathrm{~ms}$ and $165 \mathrm{~ms}$ )

later. The white lines show approximate palate locations, superimposed

over the images. Arrows 1 and 2 in the waveform and spectrogram indicate an approximation of the image times.

\subsection{Results}

In the / sm/ sequence (Fig. 3), comparison of the spectrogram and a video of the mouth show that even in a case where the $/ \mathrm{m} /$ is completely devoiced, the mouth still makes the bilabial closure for the $/ \mathrm{m} /$. Image 1 shows an example of the alveolar constriction for the $/ \mathrm{s} /$, and a few frames 


\section{Image 1}

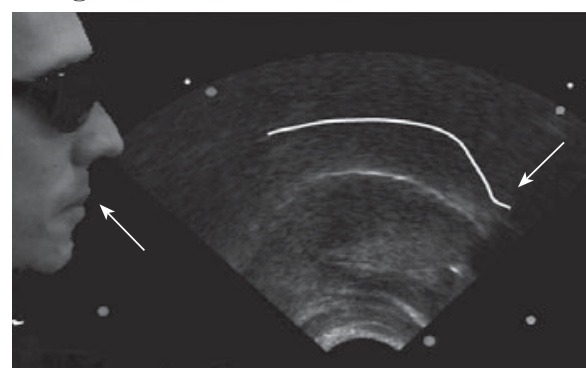

d

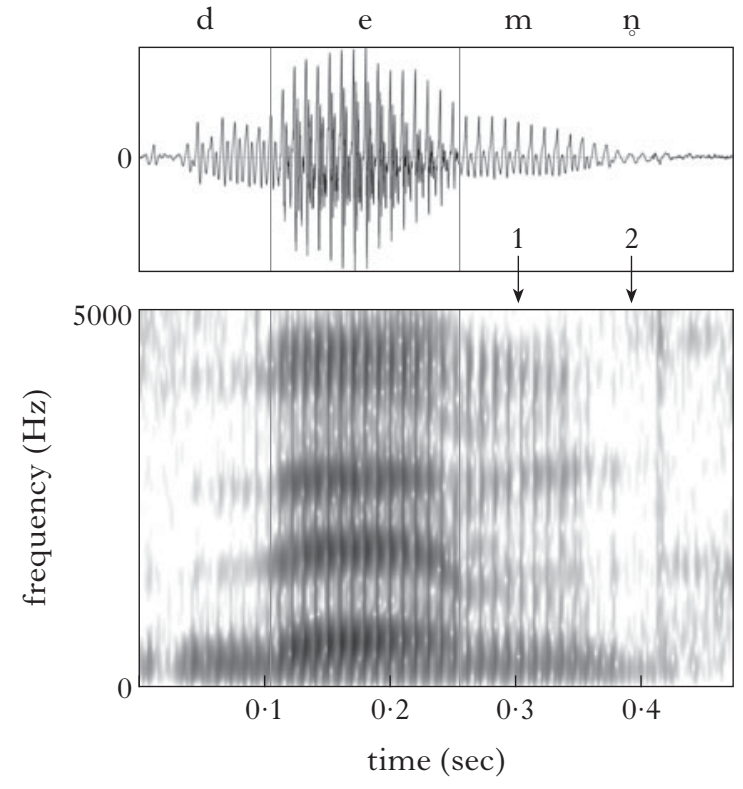

Figure 4

Image 2

n

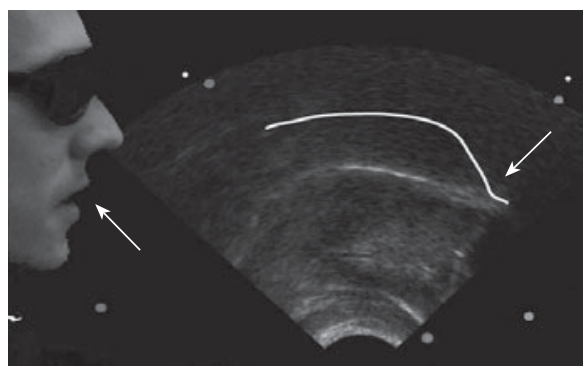


For the $/ \mathrm{mn} /$ cluster (Fig. 4), the video image shows a bilabial closure in Image 1 for the $/ \mathrm{m} /$. A few frames later, in Image 2, the video image shows the release of the bilabial closure, and the ultrasound image shows a closure at the alveolar ridge. All tokens with $/ \mathrm{mn} /$ showed an alveolar gesture for the devoiced $/ \mathrm{n} /$. The question in this experiment is whether the oral gesture for the second consonant in the $/ \mathrm{sm} /$ and $/ \mathrm{mn} /$ clusters occurs. Because $100 \%$ of tokens displayed these gestures, we do not perform any statistical analysis for these data.

\subsection{Discussion}

This experiment shows clearly that the cluster's nasal is not deleted, because the gestures for its oral closure take place in all tokens. The ultrasound's time resolution does not provide detail on when the $/ \mathrm{m} /$ ceases and the $/ \mathrm{n} /$ begins, or exactly when voicing ceases. Therefore, we do not attempt to determine how much voiceless nasalisation there is from this data, but rather use the ultrasound data solely to confirm that the gesture for the (second) nasal does occur. Experiment 2 provides evidence that the (second) nasal is not deleted in either the $/ \mathrm{sm} /$ or $/ \mathrm{mn} /$ cluster.

\section{Experiment 3: oral and nasal airflow}

Acoustic analysis cannot determine directly whether devoiced nasals, defined as nasal airflow during a time of voiceless oral closure, are present, because devoiced nasal airflow can produce such low-amplitude noise that it may not be clear in the acoustic signal. (This may be especially so because the Romanian devoiced nasals are in coda position.) The voiceless gaps in the results of Experiment 1, which are clearly delimited by another sound and a release of the nasal, are good evidence for the presence of devoiced nasals, and the finding in Experiment 2 that the oral closure is made for the nasal helps confirm this. However, aerodynamic evidence (Experiment 3) is the most direct indication of a voiceless nasal, because it can show whether there is nasal airflow during a voiceless portion of the sound. Experiment 3 also provides a further test for differences among word-final environments, because additional measurements are possible for the aerodynamic data.

\subsection{Methods}

Subjects. There was one speaker for this experiment (not a participant in Experiment 1). The speaker was a female native Romanian speaker from the Ardeal region who moved to the United States as a young adult. Three speakers were initially recorded, but the other two speakers were excluded because of abnormally careful speech. One speaker stated that 
(a)

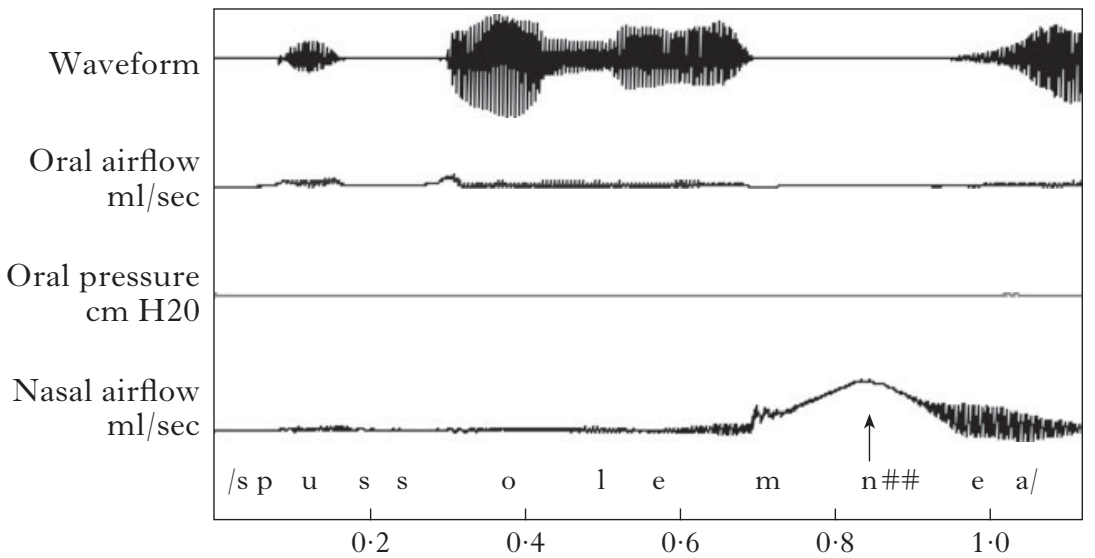

(b)

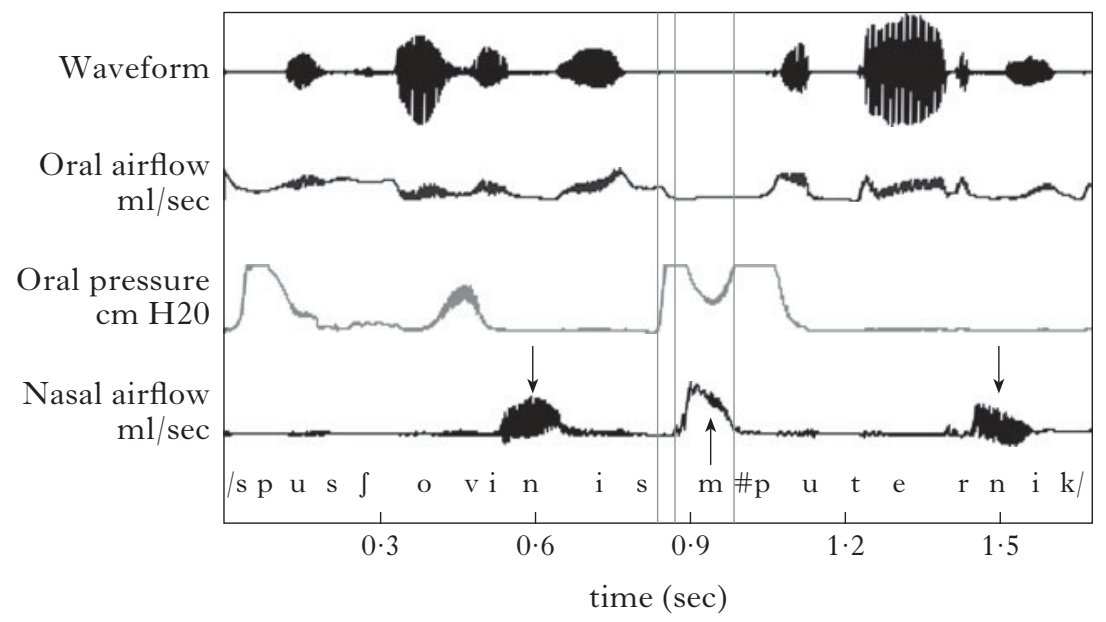

Figure 5

Waveform, oral airflow, oral pressure and nasal airflow in (a) /solemn/ 'solemn' and (b) / Jovinism/ 'chauvinism', in the frame sentences given in Table I. Voiced nasal airflow is indicated by the downward pointing arrows, and voiceless nasal airflow by the upward pointing arrows. No oral pressure was recorded in (a). In (b), the portion between the first two vertical lines indicates the oral closure overlap, with oral pressure similar to that of a voiceless stop. The portion between the second and third vertical lines shows the duration of devoiced nasal airflow.

his speech during the experiment was not natural, perhaps because of discomfort with the airflow equipment. The second speaker himself feels that his usual style of speaking is not typical, and is excessively hyperarticulated. He and his spouse, who was the first speaker, both indicated this during post-experiment debriefing. Because of the difficulty of recruiting native Romanian speakers in Tucson, it was not possible to obtain additional, more typical, speakers for this experiment. Although it is 
unfortunate to exclude two out of the three speakers, studies on a small immigrant group's language have to use more varied speakers than studies on the dominant surrounding language, and both of the excluded speakers indicated that they did not believe their speech during the experiment was representative of normal Romanian speech. Both of the excluded speakers failed to devoice at all during the experiment, which may indicate that a hyperarticulated style of speaking Romanian lacks the nasal devoicing process, or could be an idiosyncrasy of these speakers.

Materials. The materials were the same as in Experiment 1 (both $1 \mathrm{a}$ and $1 \mathrm{~b})$.

Procedure. The materials were identical to those of Experiment 1. While speakers read the sentences, oral and nasal airflow data were recorded using SciCon R\&D's aerodynamic equipment and MacQuirer. Subjects held the oral mask over the mouth, with a small tube extending just inside the lips to record oral pressure, and wore a second mask over the nose to record nasal airflow. Airflow and pressure measurements were calibrated using Scicon R\&D's calibration unit. Oral pressure measurements were only available for two frame sentence blocks (hence two wordfinal environments and half of the word-medial data) because of a problem in positioning the oral pressure tube (Fig. 5a), but oral and nasal airflow measurements were available for all tokens. Amplitude of oral pressure measurements often exceeded maximum amplitude (Fig. 5b), but oral pressure data were only used to locate time of oral closure, so the peak pressure value is not necessary.

Duration of the voiced and the voiceless parts of the nasal airflow were measured for all items, as well as whether both were present. Nasal airflow was defined as an increase from the baseline amplitude of nasal flow. Voicing is visible as periodic movements along the nasal flow line and in the waveform. Furthermore, measures were made of duration from onset of oral pressure to the onset of nasal airflow for $/ \mathrm{mn} /$ in tokens where oral pressure data were available, because the increase in oral pressure began before the onset of nasal airflow (Fig. 5b). Figure 5b also illustrates the difference between a voiced and a voiceless nasal. Figure 5 a shows an example of oral and nasal airflow in an $/ \mathrm{mn} /$ cluster with no oral pressure data recorded.

\subsection{Results}

4.2.1 $/ \mathrm{sm} /$ items. Utterance-final $/ \mathrm{m} /$ in $/ \mathrm{sm} /$ clusters was devoiced categorically. In the other word-final environments, complete devoicing was a common, but variable, realisation. Figure 6 shows the aerodynamic duration data and the number of completely devoiced items for each condition.

One-factor between-items ANOVAs testing over items ${ }^{4}$ showed a significant effect of Phonetic Environment on each dependent variable,

4 All statistical analyses in Experiment 2 are across items, because there is one speaker. 


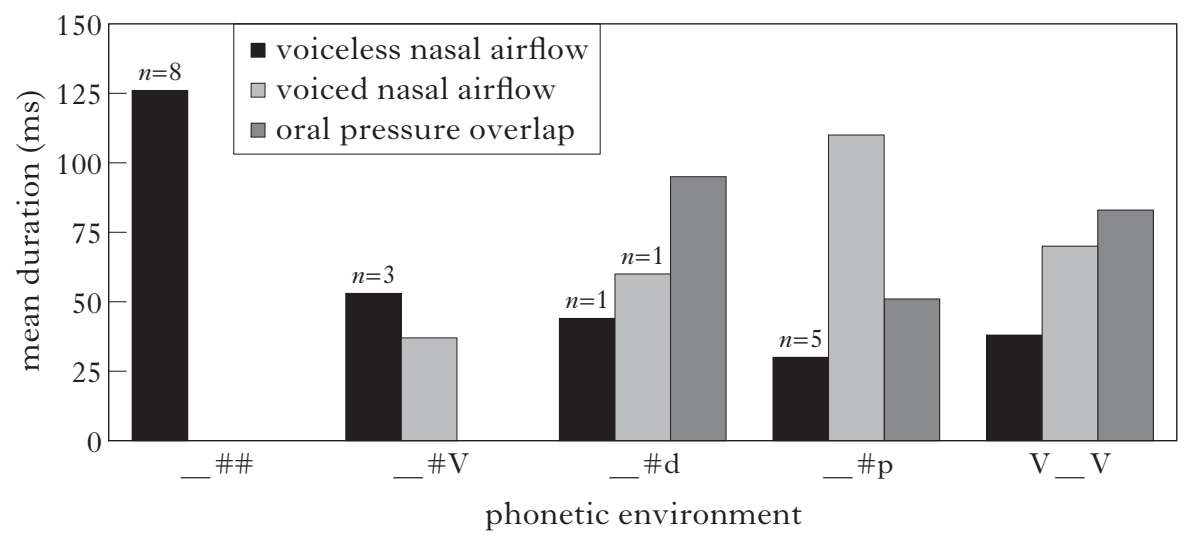

Figure 6

Durations of voiceless nasal airflow, voiced nasal airflow and oral pressure overlap (the period from onset of oral pressure to onset of nasal flow) in $/ \mathrm{sm} /$ clusters, by the following environment. Counts above columns indicate the number of devoiced or voiced items out of eight that occurred with only voiceless or voiced airflow, but not with both.

comparing among only the environments that have data for each measure (duration from onset of oral pressure to onset of nasal airflow: $F(2,12)=$ $5 \cdot 239, \mathrm{p}<0.05$; voiceless nasal airflow duration: $\mathrm{F}(3,33)=6 \cdot 442, \mathrm{p}<0 \cdot 05$; voiced nasal airflow duration: $\mathrm{F}(3,25)=4 \cdot 028, \mathrm{p}<0 \cdot 05)$. Post hoc comparisons showed that the utterance-final environment had significantly longer voiceless nasal airflow than each of the other word-final environments (_\#\#vs. _\#V: $\mathrm{F}(1,13)=5 \cdot 557$; _\#\# vs. _\#d: $\mathrm{F}(1,12)=5.926$; \#\# vs. _ \#p: $\mathrm{F}(1,12)=8 \cdot 491$; all $\mathrm{p}$ 's $<0.05)$. The count data have quantities too small for reliable statistical analysis, but it is clear that devoicing was most common in utterance-final environment. Thus the utterance-final environment had longer and more frequent devoicing than other word-final environments, including the pre-voiceless stop ( $\# \mathrm{p})$ environment. This again shows two types of gradience in devoicing: in both how often the process happens and to what extent it happens in a given token. Utterance-final environment also differed in duration of voiced nasal airflow, since it had none. Devoicing did not seem to differ among the three word-final non-utterance-final environments.

4.2.2 $/ \mathrm{mn} /$ items. Figure 7 presents the aerodynamic duration and count results for $/ \mathrm{mn} /$ and single $/ \mathrm{m} /$ or $/ \mathrm{n} /$ items. ANOVAs were performed for each of the continuous measures (voicing duration, devoiced duration and amplitude), with Phonetic Environment (__\#\#, _ \#V, _ \#d and _ \#p, within items) and Nasal Sequence Type $(/ \mathrm{mn} /$ cluster $v$ s. single $/ \mathrm{m} /$ or $/ \mathrm{n} /$, between items) as the factors. The medial environment was excluded to allow for the two-factor design. For voiced duration (Fig. 7a), both 
(a)

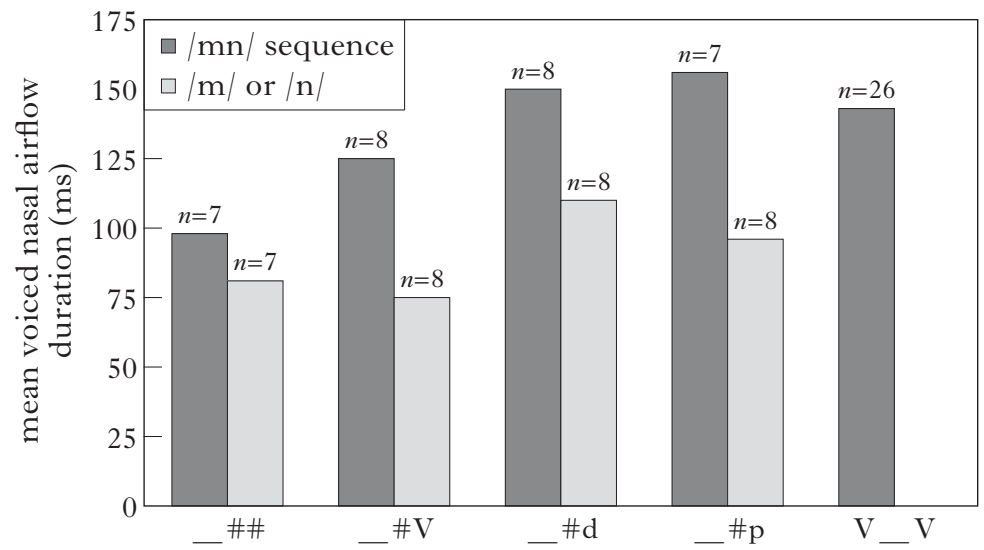

(b)

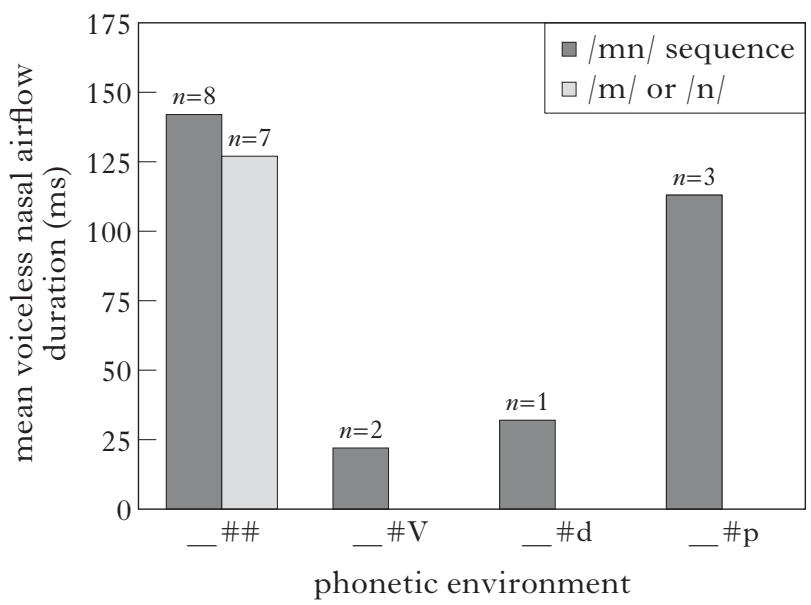

Figure 7

Durations of $/ \mathrm{mn} /$ clusters and $/ \mathrm{m} /$ and $/ \mathrm{n} /$ single nasals.

(a) Voiced nasal airflow; (b) Voiceless nasal airflow.

Environment $(\mathrm{F}(3,33)=5.991, \mathrm{p}<0.05)$ and Nasal Sequence Type $(\mathrm{F}(1,11)=21 \cdot 877, \mathrm{p}<0.05)$ had significant effects, but they did not interact $(\mathrm{F}(3,33)=1 \cdot 857, \mathrm{p}>0 \cdot 05)$. The voiced nasal duration was greater for $/ \mathrm{mn} /$ sequences than for single $/ \mathrm{m} /$ or $/ \mathrm{n} /$, a parallel with the acoustic results in Experiment 1. Voiced nasal duration was shortest for the utterance-final environment, indicating greater devoicing for utterancefinal $/ \mathrm{mn} /$ than for other word-final environments. Post hoc comparisons showed that this effect was significant for the comparisons with all but one word-final environment (_\#\# vs. _\#V: $\mathrm{F}(1,13)=4 \cdot 205, \mathrm{p}=0 \cdot 061$; \#\# vs. _\#d: $\mathrm{F}(1,13)=8 \cdot 719, \mathrm{p}<0 \cdot 05 ; \ldots \#$ _ $\overline{14} \cdot 315, \mathrm{p}<\overline{0} \cdot 005)$. 


\section{Benjamin V. Tucker and Natasha Warner}

Among / $\mathrm{mn}$ / items, duration of voiceless nasal airflow was longest for the utterance-final environment, and this was also the only environment to have voiceless nasal airflow in all, or even most, tokens (Fig. 7b). Because of the small number of tokens with voiceless nasal airflow duration in some conditions, no statistical analysis was conducted on this measure. However, the pattern of results supports the finding of greater devoicing for utterance-final environment than other word-final environments. The results in Fig. 7b seem to indicate visually that the word-final prevoiceless stop (_ $\# \mathrm{p})$ condition patterned with the utterance-final condition rather than with the word-final pre-voicing conditions. However, the small quantity of data for which duration of voiceless nasal flow in _\#p environment can be evaluated makes this result inconclusive.

\subsection{Discussion}

Based on the presence of voiceless nasal airflow in the $/ \mathrm{sm} /$ and $/ \mathrm{mn} /$ clusters, it is clear that there is devoicing in all utterance-final tokens and many other word-final tokens. For $/ \mathrm{sm} /$ clusters, $100 \%$ of utterance-final tokens showed complete devoicing (only voiceless nasal airflow), and all other word-final tokens but one showed at least some voiceless nasal airflow. For medial $/ \mathrm{sm} /$ clusters, there was some voiceless nasal airflow, but no token lacked a voiced nasal airflow portion completely. Thus, utterance-final tokens showed consistent and complete devoicing, other word-final environments had variable complete devoicing and considerable partial devoicing, and medial tokens had only a small voiceless nasal portion. For the $/ \mathrm{mn} /$ cluster, there was voiceless nasal airflow during all utterance-final tokens and some other word-final tokens, but not during medial tokens.

These results confirm the major findings of Experiments 1a, 1b and 2: Romanian nasals which are the second consonant of a coda cluster do have variable devoicing, but are not deleted, the same nasals do not devoice when the clusters are split across a syllable boundary and there is more devoicing for the $/ \mathrm{sm} /$ cluster than the $/ \mathrm{mn} /$ cluster. These findings confirm the conclusion from the acoustic data that both syllable structure and low-level phonetic assimilation are involved in Romanian nasal devoicing. The coda $v s$. medial difference shows the effect of syllable structure, and the $/ \mathrm{sm} /$ vs. $/ \mathrm{mn} /$ difference (where $/ \mathrm{sm} /$ could have assimilation to the voiceless $/ \mathrm{s} /$ ) confirms the role of assimilation. An interesting effect of assimilation is that partially devoiced nasals in $/ \mathrm{sm} /$ and in $/ \mathrm{mn} /$ have quite different timing: if the nasal in $/ \mathrm{sm} /$ is partially devoiced, it begins voiceless in assimilation to the $/ \mathrm{s} /$ and then becomes voiced. If the second nasal in $/ \mathrm{mn} /$ is partially devoiced, though, it begins voiced and then becomes voiceless.

As in the previous experiments, the devoicing in Experiment 3 cannot be attributed entirely to assimilation: the $/ \mathrm{mn} /$ cluster, even when followed by a word beginning with a voiced segment (e.g. /somn o dat $\Lambda$ / 'sleep once' or /somn de dows or ${ }^{\mathrm{j}}$ / 'sleep twice'), often had voiceless nasal 
airflow. Thus, there was partial devoicing in some tokens even when there were no voiceless segments in the environment whatsoever, on either side of the nasal. This can be considered a case of paradigm uniformity applied to a low-level phonetic characteristic (partial devoicing), in that the devoicing in assimilation-to-voicelessness environments is transferred to the otherwise fully voiced environment. Steriade (2000) argues that several other phenomena, e.g. the failure to flap in the English word militaristic, reflect the fact that speakers keep the phonetic form the same as in other forms of the morpheme (i.e. unflapped military). Steriade further points out that some such phenomena, like flapping, seem more phonetic than phonological, based on the fact that they use non-contrastive segments. The Romanian partial devoicing is not only not contrastive, it also seems to be far more phonetic than the cases which Steriade analyses, as it represents the devoicing of just part of one segment. We feel that applying devoicing because of paradigm uniformity is a more abstract and phonological aspect of the speech production process than simple assimilation to a voiceless neighbouring segment, even though what the paradigm uniformity transfers is a rather phonetic characteristic (partial devoicing). Transferring an alternation across environments is itself an abstract and more phonological process. We will revisit the meaning of more phonetic $v s$. more phonological processes below.

Experiment 3 also allows conclusions beyond those of Experiment 1: several measures showed greater or more frequent devoicing utterancefinally than in other word-final environments. That is, words like / basm/ or /somn/ are more likely to be devoiced if they occur at the end of the utterance than if they are followed by another word, even if that following word begins with a voiceless segment. Specifically, the $/ \mathrm{sm} /$ cluster more often showed complete devoicing (only voiceless nasal airflow), and the $/ \mathrm{mn} /$ cluster more often had partial devoicing (some voiceless nasal airflow) in utterance-final position than in other word-final environments. Voiceless nasal airflow in the $/ \mathrm{sm} /$ clusters also lasted significantly longer, and voiced nasal airflow in $/ \mathrm{mn} /$ significantly shorter, than for almost all other word-final environments. In total, these effects strongly suggest that devoicing is greater at a higher-level prosodic boundary: an utterance boundary leads speakers to devoice more strongly than they would at just a word boundary. It is particularly important that the utterance-final durations differed significantly from the word-final pre-voiceless (_\# $\#$ ) environment, and the counts of devoicing show the same pattern. Stronger devoicing at utterance boundaries cannot be an artefact of assimilation to voicelessness at the edge of the utterance, or one would find equal devoicing before an upcoming word beginning with voiceless $/ \mathrm{p} /$. Instead, it is the utterance boundary itself, not the target of following voicelessness, that leads to greater devoicing.

A surprising result is that devoiced nasal airflow appeared in utterancefinal single $/ \mathrm{m} /$ or $/ \mathrm{n} /$ nasals, not just in the clusters. The early literature (Petrovici 1930, Vasiliu 1965) does not mention devoicing of single final nasals. Single nasal devoicing may indicate some low-level phonetic 


\section{Benjamin V. Tucker and Natasha Warner}

devoicing caused by the end of utterance. However, several measures showed greater, more frequent and more widespread devoicing in clusters, suggesting that any devoicing as assimilation to the end of the utterance is in addition to a more phonological devoicing process that applies to clusters. Since only one speaker could be examined for the airflow data, devoicing in utterance-final single nasals could also be unique to the speaker. However, Experiment 1b (with different speakers) also showed some word-final single nasal tokens with a voiceless gap and a nasal release, suggesting that a small amount of devoicing of single final nasals is typical.

Another unexpected result in Experiment 3 is the frequent labial closures before the onset of nasal airflow. The data show a period of elevated oral pressure before nasal airflow begins, indicating a brief bilabial 'emergent stop' (Ohala 1975, 1997). This emergent [p] is probably not very perceptually salient. However, when native English listeners hear Romanian devoiced $/ \mathrm{sm} /$ sequences, they often perceive $/ \mathrm{sp} /$ rather than some variant of $/ \mathrm{sm} /$. English listeners may be attending to the emergent stop, while Romanian listeners attend to the voiceless nasal.

\section{General discussion}

\subsection{Summary of results}

The experiments above have shown that there is full or partial devoicing of the final nasal in two kinds of Romanian word-final consonant clusters. For the $/ \mathrm{sm} /$ cluster, complete devoicing is common, and the remaining tokens generally show partial devoicing. For the $/ \mathrm{mn} /$ cluster, partial devoicing predominates. Convergent data from several acoustic (Experiment 1 ) and aerodynamic (Experiment 3 ) measures confirm this pattern, for both clusters. The same clusters, when split across a syllable boundary (e.g. / basmul/), show at most a small indication of partial devoicing, and very few measures give evidence of any devoicing in this medial environment. Furthermore, single $/ \mathrm{m} /$ and $/ \mathrm{n} /$ not in clusters show some devoicing, particularly when utterance-final, but far less than the nasals in clusters.

Experiment $1 \mathrm{~b}$ shows indirectly (through duration measures) and Experiment 2 shows directly (through gestural evidence) that the claimed Romanian nasal devoicing is indeed devoicing rather than deletion. Finally, Experiment 3 shows aerodynamic evidence from several measures indicating that devoicing is stronger and more common in utterance-final position than in other word-final positions. None of the measures in either Experiments 1 or 3, however, reliably shows a difference between wordfinal before a voiceless-initial word $(\ldots \# p)$ and a voicing-initial word $\left(\ldots \# \mathrm{~d}\right.$ or $\left.\_\# \mathrm{~V}\right)$. Thus it appears that devoicing in the target clusters is strongest in utterance-final position, present but weaker equally in all other word-final environments and nearly absent in word-medial environment. Although individual measures do indicate some differences 
among the various word-final but utterance-medial environments, the overall pattern of evidence suggests that these conditions $(\ldots \# \mathrm{p}, \ldots \# \mathrm{~d}$, _ $\# \mathrm{~V})$ do not consistently differ for devoicing.

\subsection{Comparison to other languages' contrastive voiceless nasals}

The past literature on phonemically voiceless nasals has documented partially voiced nasals in Burmese and Icelandic, with the voicing at the end of the nasal, and nasals in Angamese that are either entirely voiceless or that begin with a small amount of voicing (Dantsuji 1986, Bhaskararao \& Ladefoged 1991, Blankenship et al. 1993, Ladefoged \& Maddieson 1996, Jessen \& Pétursson 1998). Romanian, however, appears to include both completely and partially devoiced nasals in the same language, at least in the $/ \mathrm{sm} /$ cluster. Some past literature on voiceless nasals in other languages has claimed that the reason for speakers to produce some voicing during them is to make stronger perceptual cues to place of the nasal available, since place cues in voiceless nasal airflow are extremely weak (Ohala 1975, Dantsuji 1986, Bhaskararao \& Ladefoged 1991). It may be that Romanian devoiced nasals do not require voicing for place cues because they are allophonic, and because the alternation applies only in very limited circumstances (a nasal which is the second segment of a coda cluster), so there are very few clusters in which a listener would have to recover the place of the voiceless nasal.

\subsection{The effect of prosodic boundary strength}

Comparison among the various word-final environments, and of the word-final to the medial environment, leads to several conclusions about which levels of linguistic structure contribute to Romanian nasal devoicing. First, it is clear that there is widespread devoicing (at least partial) in all word-final environments, whereas there is little evidence of any devoicing at all in medial clusters that are split across a syllable boundary, as in /basmul/, with the second nasal in onset position. This is in line with the early literature (Petrovici 1930, Vasiliu 1965). Because Romanian does not have $/ \mathrm{sm} /$ or $/ \mathrm{mn} /$ clusters followed by another consonant within the word (Chitoran 2001), it is not possible to test whether it is the word boundary or the syllable boundary that conditions devoicing, but it is clear that either a syllable or a word boundary following the cluster causes devoicing, relative to the absence of any prosodic boundary after the cluster.

Turning to higher levels of the prosodic hierarchy, the greater and more frequent devoicing for utterance-final clusters than for other word-final clusters shows that speakers strengthen devoicing at the utterance-level prosodic boundary. This result cannot stem from assimilation to voicelessness at the end of the utterance, because the utterance-final environment shows stronger devoicing than even the word-final pre-voiceless 


\section{Benjamin V. Tucker and Natasha Warner}

environment (e.g. /a spus basm puternic/ 'said 'fairy-tale' powerfully'). Experiment 3 (aerodynamics) shows this difference clearly. While it is based on just one speaker, four measures (two of frequency of devoicing and two of duration), representing both $/ \mathrm{sm} /$ and $/ \mathrm{mn} /$ clusters, show this pattern. Devoicing is thus more extreme utterance-finally than wordfinally, even before a voiceless segment.

Devoicing of a nasal is an unusual phenomenon in which to find a prosodic boundary strengthening effect. Strengthening at higher levels of prosodic boundaries has previously been shown through stronger consonant and vowel articulations (especially degree of tongue closure during consonants), duration and to some extent through degree of tongue displacement for gestures (see Keating et al. 2003, Byrd et al. 2005, Byrd et al. 2006 and others cited above). Syllable structure has widely been shown to influence gestural timing and gestural overlap (Krakow 1993, 1999, Chitoran et al. 2002, Gick et al. 2006, Byrd \& Choi 2010) and Byrd \& Choi show that coda consonant clusters have less overlap between the consonants when they are followed by higher prosodic boundaries. However, the current work shows a rather different influence of the hierarchy of prosodic boundaries: it shows that an utterance boundary causes more devoicing of the preceding nasal than a word boundary does. Thus the prosodic domain effect strengthens the presence of a cross-linguistically rare sound type that does not otherwise occur in the language, rather than simply creating a stronger articulation of a more typical sound.

It could be argued that nasal devoicing is a weakening effect rather than a strengthening effect. Voiceless nasals are acoustically very weak sounds, providing few perceptual cues other than to their voicelessness (Ohala 1975, Dantsuji 1986). Barnes (2006) treats devoicing as weakening, even for segment types other than nasals. For the current results to reflect prosodic domain strengthening, nasal devoicing has to be viewed as a strengthening process. The current results do show greater devoicing at progressively higher prosodic boundaries (syllable or word, utterance), which resembles past prosodic hierarchy results for other types of strengthening. Devoicing a nasal can be considered strengthening, because it makes the nasal more obstruent-like, even though this also results in a weaker percept. This suggests that the meaning of strengthening depends both on the segment type and on whether one evaluates perceptual cues as well as articulation and acoustics. Overall, domain-dependent strengthening is more complicated than studies of a single segment type might indicate.

The finding of more devoicing at higher-level boundaries might seem surprising, given Byrd \& Choi's (2010) finding that coda consonant clusters are less overlapped when followed by stronger boundaries. This would indeed be surprising if devoicing were primarily a matter of overlapping a voiceless gesture with a neighbouring nasal, because our data would show greater, not lesser, overlap before higher boundaries. However, as discussed in the following section, Romanian nasal devoicing 
is only partly a matter of assimilation to neighbouring voicelessness. Since the devoicing is not truly a result of gestural overlap, our finding of greater devoicing before the utterance boundary is not in conflict with Byrd \& Choi's finding.

\subsection{The effect of low-level phonetic assimilation}

Several aspects of the current results indicate that simple assimilation to surrounding voicelessness influences Romanian nasal devoicing, but does not entirely cause it. The differences between the $/ \mathrm{sm} /$ and $/ \mathrm{mn} /$ clusters, showing that $/ \mathrm{sm} /$ is far more likely to have complete devoicing while $/ \mathrm{mn} /$ is likely to have partial devoicing, are one strong indication of an effect of assimilation to the voicelessness of the $/ \mathrm{s} /$. The difference in timing, such that partially devoiced nasals in $/ \mathrm{sm} /$ are voiceless-initial and those in $/ \mathrm{mn} /$ are voiceless-final, is another indication of the role of assimilation. Furthermore, some tokens of single $/ \mathrm{m} /$ and $/ \mathrm{n} /$ (not in clusters) also show devoicing in utterance-final position (voiceless nasal airflow in Experiment 3, and nasal releases in Experiment $1 \mathrm{~b}$ ). Since no devoicing is predicted for non-cluster, single nasals, and there is substantial evidence that this devoicing is weaker than devoicing in clusters, it seems reasonable to conclude that the weak devoicing of non-cluster nasals also reflects assimilation to following voicelessness. (However, since this single nasal devoicing is almost entirely limited to utterance-final position, this also indicates a role of the utterance domain.)

Thus at least two aspects of the data indicate that phonetic assimilation is part of the cause of nasal devoicing. However, the results show a lack of an assimilatory influence in some places where one might expect to find it. Specifically, differences among the word-final but utterance-medial environments, where the word-final target cluster is followed by a word beginning with a voiceless stop, a voiced stop or a vowel, were inconsistent or small. If phonetic assimilation were the primary influence on Romanian nasal devoicing, one would expect substantially greater devoicing in a pre-voiceless cluster $(\ldots \#)$ ) than in a cluster before voicing (_\# $\#$ and \#V), but the data failed to show this. This is in contrast to the stronger $\overline{\text { effect }}$ of the utterance boundary, which appeared consistently across several measures. Thus, we can conclude that assimilation to surrounding voicelessness does contribute to the Romanian nasal devoicing phenomenon, but that it is not the primary factor. This recalls Westbury \& Keating's (1986) conclusion that aerodynamics (and in their phrasing ease of articulation) is one influence, but not the main one, on voicing of stops within a given language. The fine phonetic detail of how particular sounds of particular languages are realised does reflect factors that are typically considered phonetic, such as aerodynamics and spread of surrounding gestures. However, other factors, which may be more abstract, may be considered more phonological and may involve acoustic similarity to other forms of the morpheme or phoneme (Westbury \& Keating 1986, Steriade 2000), are also involved. 


\section{Benjamin V. Tucker and Natasha Warner}

\subsection{What is phonetics and what is phonology?}

Throughout this paper, we have been considering some factors that cause sound patterns to be phonological, and others to be phonetic. However, we have not defined a single set of criteria for which is which. The literature includes a variety of criteria or definitions: a phenomenon may be considered phonetic if it is gradient and variable, if it is caused by biological or aerodynamic necessity, if it is too subtle to detect by ear without instrumental measurement, if it results in sounds that are not lexically distinctive in the language or in any language, if it is triggered or influenced by other factors that are considered phonetic, etc. The gradience criterion may refer to either type of gradience mentioned above: to an effect happening only in some tokens (gradience in whether it happens, e.g. only three-quarters of tokens are devoiced, but they are devoiced completely) or to an effect happening with variable strength (gradience in how much of something happens in a given token, measurable on a continuous scale such as duration, e.g. a given token is devoiced for three-quarters of its duration). A phenomenon is sometimes considered phonological if it is the opposite of these things: if it is consistent and categorical, involves only complete sounds that are distinctive and is perceptually obvious. A phenomenon may also be considered phonological if it interacts with highly abstract, phonological phenomena, such as morphophonology or foot structure. Furthermore, if an alternation seems arbitrary, so that it is not phonetically natural, it may be considered phonological.

However, there are myriad problems with these potential criteria. The field of laboratory phonology has long shown that many, if not all, phonological phenomena are gradient and variable. What is perceptually obvious vs. only detectable by instrumental measurement depends strongly on who is listening and what his/her native language is (Flege 1995). Steriade (2000) initially adopts the criterion of whether only lexically distinctive sounds are involved, so that American English flapping is a phonetic alternation. Yet flapping is nearly categorical (Patterson \& Connine 2001), and is rather noticeable perceptually (judging by introductory linguistics students' ability to notice that a flap is not a $[\mathrm{t}]$ ). Flapping seems far more phonological than some other phenomena, such as VOT being slightly longer before high vowels than non-high vowels (Ohala 1983).

Steriade goes on to conclude that we should not be trying to distinguish between phonetic and phonological phenomena, because all sound patterns are part of the same system - there is no difference between phonetics and phonology. Barnes (2006), however, argues that phonetics and phonology are very distinct systems: once a pattern caused by phonetics is phonologised, it becomes separate from the phonetics, functioning as an arbitrary pattern stipulated by the grammar. On this view, sound patterns begin as caused by biological, aerodynamic and other factors, and are then reanalysed into the abstract, arbitrary phonology. Many other authors have also made proposals on how phonetics and phonology relate as 
cognitive systems, but we choose these two as representatives of relatively extreme possibilities. We suggest, using the example of Romanian nasal devoicing, that neither the single system nor the separate systems viewpoint is sufficient. Sound patterns that are highly arbitrary, abstract, consistent and categorical are clearly not the same type as those that cause variable differences of a few milliseconds. However, we doubt that any criterion will ever suffice to separate all sound patterns into two groups, the phonetic and the phonological. Instead, it seems that what is phonetic and what is phonological is a continuum, or more likely a set of dimensions, most of them continuous. Each criterion that has been proposed to divide phonetics from phonology may be describing one dimension of a multi-dimensional space. For example, variability of application is one continuous dimension, perceptual obviousness is another, and involvement of non-contrastive sounds may be a categorical rather than continuous dimension.

In the case of Romanian nasal devoicing, we have shown that it is gradient both in how often it happens and in how much of it happens in a particular token, making it seem phonetic. We have argued that it is affected by syllable structure, which is itself both phonetic and phonological. (Syllable structure causes clearly phonetic effects in languages: being in the onset $v s$. coda affects which component gestures of a sonorant are timed closer to the vowel and which closer to the edge of the syllable (Gick et al. 2006). However, the hierarchical structure of a syllable itself, and the fact that languages treat onsets and codas differently, is part of phonology.) We have also shown that Romanian nasal devoicing is influenced by prosodic boundary strength. Like syllable structure, the prosodic hierarchy causes low-level phonetic effects, but consists of a rather abstract, phonological hierarchical structure. We have found that Romanian devoicing stems partly from assimilation to voicelessness of a neighbouring segment (a rather phonetic pattern, involving timing of an articulatory gesture), but that it also occurs where assimilation cannot cause it, suggesting that devoicing has been transferred from other environments (paradigm uniformity) in a rather abstract, phonologised way. Like Westbury \& Keating's (1986) findings about reasons for degree of voicing in obstruents, some of the causative factors for Romanian nasal devoicing appear more phonetic and some more abstract, and the phonetic and phonological aspects of the causes are intertwined.

One could simply state that a given sound pattern, for example Romanian nasal devoicing, derives from both phonetic and phonological causes. However, a more accurate characterisation than 'both phonetic and phonological factors cause the pattern' may be 'all sound patterns fall somewhere on each of several dimensions that make up what we attempt to separate into phonetics and phonology'. One can visualise the systems of phonetics and phonology as a multidimensional, largely continuous space. Most sound patterns will not fall at the phonetic end of all continua, or the phonological end of all of them, so a given pattern is relatively phonetic in some ways and relatively phonological in others. This is demonstrated by 


\section{Benjamin V. Tucker and Natasha Warner}

Romanian nasal devoicing, by Westbury \& Keating's (1986) conclusions about obstruent voicing typology and by American English flapping, as discussed above. Perhaps the colloquial usage among linguists of describing something as 'seeming phoneticy' is more useful than forcing a classification into two distinct systems, or grouping both systems together into a single one.

\section{Conclusions}

The current work provides phonetic documentation of nasal devoicing, a phenomenon that has not been widely studied experimentally. Early research (Petrovici 1930, Vasiliu 1965) claimed that certain nasals in Romanian are at least sometimes voiceless, and current research verifies this, as well as providing detail on variability in the devoicing, particularly for a case of allophonic devoicing.

The current work also demonstrates an effect of strengthening at higher-level prosodic boundaries: devoicing is greater and more frequent at utterance-boundaries than word boundaries (as reflected in work on vowels (Gordon 1998, Barnes 2006)). Finally, the current work demonstrates that the Romanian devoicing phenomenon is influenced by both relatively phonetic and relatively phonological factors. We argue that sound phenomena neither belong to one of two distinct systems (phonetics and phonology), nor belong to a single undifferentiated system (in which phonetics and phonology are the same thing). Rather, we argue that sound phenomena can be classified on several dimensions, most of them continuous, which all together make the phenomenon relatively phonetic or relatively phonological.

\section{Appendix: Target words, transcriptions and glosses}

\section{Experiment $1 \mathrm{~A}$}

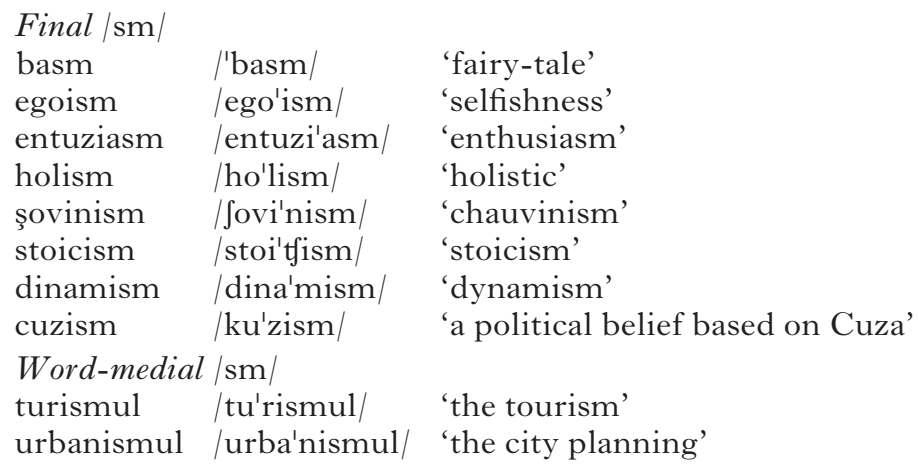




\section{Experiment 1B}

Final /mn/

\begin{tabular}{|c|c|c|}
\hline demn & /'demn/ & 'worthy' \\
\hline domn & /'domn/ & 'sir, lord' \\
\hline imn & /'imn/ & 'hymn' \\
\hline lemn & /'lemn/ & 'wood' \\
\hline pumn & /'pumn/ & 'fist' \\
\hline semn & /'semn/ & 'sign' \\
\hline solemn & /so'lemn/ & 'solemn' \\
\hline somn & /'somn/ & 'tired, sleep' \\
\hline \multicolumn{3}{|c|}{ Word-medial/mn/ } \\
\hline a îndemna & /a indem'na/ & 'to urge' \\
\hline amnezie & /amne'zie/ & 'amnesia' \\
\hline doamnă & /do'amns/ & 'lady' \\
\hline dumnezeu & /dumne'zew/ & 'god' \\
\hline gimnastică & /dzim'nastiks/ & 'gymnastics' \\
\hline înseamnă & /inse'amns/ & 'it means' \\
\hline temniţă & /'temnits $\Lambda /$ & 'jail' \\
\hline \multicolumn{3}{|c|}{ Single $/ \mathrm{m} /$ or $/ \mathrm{n} /$} \\
\hline baton & /ba'ton/ & 'stick' \\
\hline casetofon & /kaseto'fon/ & 'cassette player' \\
\hline cum & /'kum/ & 'how' \\
\hline dăm & $/ \mathrm{d} \Lambda \mathrm{m} /$ & 'we give' \\
\hline galben & /'galben/ & 'yellow' \\
\hline lacom & /'lakom/ & 'greedy' \\
\hline & /ne'am/ & 'nation, people' \\
\hline lcan & /vul'kan/ & 'volcano' \\
\hline
\end{tabular}

\section{Experiment 2}

$\begin{array}{lll}\text { /mn/ } & & \\ \text { nedemn } & \text { /ne'demn/ } & \text { 'unworthy' } \\ \text { desemn } & \text { /de'semn/ } & \text { 'appoint/designate' } \\ \text { untdelemn } & \text { /untde'lemn/ } & \text { 'cruet' } \\ \text { demn } & \text { 'demn/ } & \text { 'worthy' } \\ \text { domn } & \text { /'domn/ } & \text { 'sir, lord' } \\ \text { lemn } & \text { /'lemn/ } & \text { 'wood' } \\ \text { pumn } & \text { /'pumn/ } & \text { 'fist' } \\ \text { semn } & \text { /'semn/ } & \text { 'sign' } \\ \text { nesomn } & \text { /ne'somn/ } & \text { 'not tired' } \\ \text { solemn } & \text { /so'lemn/ } & \text { 'solemn' } \\ \text { somn } & \text { /'somn/ } & \text { 'sleep' } \\ \text { însemn } & \text { /in'semn/ } & \text { 'insignia' } \\ \text { /sm/ } & & \\ \text { basm } & \text { /'basm/ } & \text { 'fairy-tale' } \\ \text { pleonasm } & \text { /pleo'nasm/ } & \text { 'pleonasm' } \\ \text { spasm } & \text { /'spasm/ } & \text { 'spasm' } \\ \text { entuziasm } & \text { /entuzi'asm/ } & \text { 'enthusiasm' } \\ \text { fantasm } & \text { /fan'tasm/ } & \text { 'phantasm' }\end{array}$


REFERENCES

Academia Română (1996). Dicţionarul explicativ al limbii române (DEX). Bucharest: Editurii Univers Enciclopedic.

Avram, Andrei (1991). Semivocalele, semiconsoanele şi pseudovocalele în românia. Studii şi cercetări lingvistice 5-6. 193-205.

Barnes, Jonathan (2006). Strength and weakness at the interface : positional neutralization in phonetics and phonology. Berlin \& New York: Mouton de Gruyter.

Bhaskararao, Peri \& Peter Ladefoged (1991). Two types of voiceless nasals. Fournal of the International Phonetic Association 21. 80-88.

Blankenship, Barbara, Peter Ladefoged, Peri Bhaskararao \& Nichumeno Chase (1993). Phonetic structures of Khonoma Angami. UCLA Working Papers in Phonetics 84. 127-141.

Boersma, Paul \& David Weenink (2005). Praat: a system for doing phonetics by computer (version 4.3.19). http://www.praat.org/.

Bombien, Lasse, Christine Mooshammer, Philip Hoole, Tamara Rathcke \& Barbara Kühnert (2007). Articulatory strengthening in initial German / kl/ clusters under prosodic variation. In Trouvain \& Barry (2007). 457-460.

Botma, Bert (2004). Phonological aspects of nasality : an element-based dependency approach. PhD dissertation, University of Leiden.

Browman, Catherine P. \& Louis Goldstein (1992). Articulatory phonology: an overview. Phonetica 49. 155-180.

Byrd, Dani \& Susie Choi (2010). At the juncture of prosody, phonology, and phonetics: the interaction of phrasal and syllable structure in shaping the timing of consonant gestures. In Cécile Fougeron, Barbara Kühnert, Mariapaola D'Imperio \& Nathalie Vallée (eds.) Laboratory phonology 10. Berlin \& New York: Mouton de Gruyter.

Byrd, Dani, Jelena Krivokapić \& Sungbok Lee (2006). How far, how long: on the temporal scope of prosodic boundary effects. FASA 120. 1589-1599.

Byrd, Dani, Sungbok Lee, Daylen Riggs \& Jason Adams (2005). Interacting effects of syllable and phrase position on consonant articulation. $\mathcal{F} A S A$ 118. 3860-3873.

Byrd, Dani \& Elliot Saltzman (2003). The elastic phrase: modeling the dynamics of boundary-adjacent lengthening. FPh 31. 149-180.

Chitoran, Ioana (2001). The phonology of Romanian: a constraint-based approach. Berlin \& New York: Mouton de Gruyter.

Chitoran, Ioana (2002). A perception-production study of Romanian diphthongs and glide-vowel sequences. Fournal of the International Phonetic Association 32. 203-222.

Chitoran, Ioana, Louis Goldstein \& Dani Byrd (2002). Gestural overlap and recoverability: articulatory evidence from Georgian. In Carlos Gussenhoven \& Natasha Warner (eds.) Laboratory Phonology 7. Berlin \& New York: Mouton de Gruyter. 419-447.

Cho, Taehong (2005). Prosodic strengthening and featural enhancement: evidence from acoustic and articulatory realizations of $/ \mathrm{a}$, i/ in English. FASA 117. 3867-3878.

Dantsuji, Masatake (1986). Some acoustic observations on the distinction of place of articulation for voiceless nasals in Burmese. Studia Phonologica 20. 1-11.

Flege, James Emil (1995). Second-language speech learning: theory, findings, and problems. In Winifred Strange (ed.) Speech perception and linguistic experience: issues in cross-language research. Timonium, Md.: York Press. 229-273.

Fougeron, Cécile \& Patricia A. Keating (1997). Articulatory strengthening at edges of prosodic domains. FASA 101. 3728-3740.

Gick, Bryan, Fiona Campbell, Sunyoung Oh \& Linda Tamburri-Watt (2006). Toward universals in the gestural organization of syllables: a cross-linguistic study of liquids. FPh 34. 49-72. 
Gordon, Matthew (1998). The phonetics and phonology of non-modal vowels: a cross-linguistic perspective. BLS 24. 93-105.

Huffman, Marie \& Rena Krakow (eds.) (1993). Nasals, nasalization, and the velum. San Diego: Academic Press.

Jessen, Michael \& Magnús Pétursson (1998). Voiceless nasal phonemes in Icelandic. Fournal of the International Phonetic Association 28. 43-53.

Keating, Patricia A. (2006). Phonetic encoding of prosodic structure. In Jonathan Harrington \& Marija Tabain (eds.) Speech production : models, phonetic processes, and techniques. New York: Psychology Press. 167-186.

Keating, Patricia A., Taehong Cho, Cécile Fougeron \& Chai-Shune Hsu (2003). Domain-initial articulatory strengthening in four languages. In John Local, Richard Ogden \& Rosalind Temple (eds.) Phonetic interpretation: papers in laboratory phonology VI. Cambridge: Cambridge University Press. 145-163.

Krakow, Rena A. (1993). Nonsegmental influences on velum movement patterns: syllables, sentences, stress, and speaking rate. In Huffman \& Krakow (1993). 87-116.

Krakow, Rena A. (1999). Physiological organization of syllables: a review. $\mathscr{F P h} 27$. $23-54$.

Ladefoged, Peter \& Ian Maddieson (1996). The sounds of the world's languages. Oxford \& Malden, Mass. : Blackwell.

Maddieson, Ian (1984a). Patterns of sounds. Cambridge: Cambridge University Press.

Maddieson, Ian (1984b). The effects on $\mathrm{F}_{0}$ of a voicing distinction in sonorants and their implications for a theory of tonogenesis. $\mathscr{F P h ~ 1 2 . 9 - 1 5 . ~}$

Marin, Stefania (2007). An articulatory modeling of Romanian diphthong alternations. In Trouvain \& Barry (2007). 453-456.

Ohala, John J. (1975). Phonetic explanations for nasal sound patterns. In Charles A. Ferguson, Larry M. Hyman \& John J. Ohala (eds.) Nasálfest: papers from a symposium on nasals and nasalization. Stanford: Language Universals Project, Stanford University. 289-316.

Ohala, John J. (1983). The origin of sound patterns in vocal tract constraints. In Peter F. MacNeilage (ed.) The production of speech. New York: Springer. 189-216.

Ohala, John J. (1990). There is no interface between phonetics and phonology: a personal view. $\mathscr{F P h} \mathbf{1 8}$. 153-171.

Ohala, John J. (1997). Emergent stops. Proceedings of the 4th Seoul International Conference on Linguistics [SICOL]. Seoul: Linguistic Society of Korea. 84-91.

Ohala, John J. \& Manjari Ohala (1993). The phonetics of nasal phonology: theorems and data. In Huffman \& Krakow (1993). 225-249.

Patterson, David \& Cynthia M. Connine (2001). Variant frequency in flap production: a corpus analysis of variant frequency in American English flap production. Phonetica 58. 254-275.

Petrovici, Emil (1930). De la nasalité en Roumain. Cluj: Institul de Arte Grafice 'Ardealul'.

Steriade, Donca (2000). Paradigm uniformity and the phonetics-phonology boundary. In Michael B. Broe \& Janet B. Pierrehumbert (eds.) Papers in laboratory phonology $V$ : acquisition and the lexicon. Cambridge: Cambridge University Press. 313-334.

Stevens, Kenneth N. (1998). Acoustic phonetics. Cambridge, Mass: MIT Press.

Tabain, Marija (2003a). Effects of prosodic boundary on $/ \mathrm{aC} /$ sequences: acoustic results. FASA 113. 516-531.

Tabain, Marija (2003b). Effects of prosodic boundary on /aC/ sequences: articulatory results. $\mathcal{F} A S A$ 113. 2834-2849.

Tabain, Marija \& Pascal Perrier (2005). Articulation and acoustics of /i/ in preboundary position in French. $\mathscr{F P h ~ 3 3 . ~ 7 7 - 1 0 0 . ~}$

Tiede, Mark, Stefanie Shattuck-Hufnagel, Beth Johnson, Satrajit Ghosh, Melanie Matthies, Madjid Zandipour \& Joseph Perkell (2007). Gestural phasing in /kt/ 


\section{Benjamin V. Tucker and Natasha Warner}

sequences contrasting within and cross word contexts. In Trouvain \& Barry (2007). 521-524.

Trouvain, Jürgen \& William J. Barry (eds.) (2007). Proceedings of the 16th International Congress of Phonetic Sciences. Dudweiler, Saarbrücken: Pirrot.

Tsuchida, Ayako, Abigail C. Cohn \& Masanobu Kumada (2000). Sonorant devoicing and the phonetic realization of [spread glottis] in English. Working Papers of the Cornell Phonetics Laboratory 13. 167-181.

Vasiliu, Emanuel (1965). Fonologia limbii române. Bucarest: Editura Ştiinţifică.

Warner, Natasha, Allard Jongman, Joan Sereno \& Rachèl Kemps (2004). Incomplete neutralization and other sub-phonemic durational differences in production and perception: evidence from Dutch. $\mathscr{F P h}$ 32. 251-276.

Westbury, John R. \& Patricia A. Keating (1986). On the naturalness of stop consonant voicing. $\mathscr{F} L 22$. 145-166. 